\title{
Climate and environmental monitoring for decision making
}

Pietro Ceccato ${ }^{1 *}$, Katia Fernandes ${ }^{1}$, Daniel Ruiz ${ }^{1,2}$ and Erica Allis $^{1}$

\begin{abstract}
As human populations grow, so do the resource demands imposed on ecosystems and the impacts of our global footprint. Natural resources are not invulnerable, nor infinitely available. The environmental impacts of anthropogenic actions are becoming more apparent - air and water quality are increasingly compromised, pests and diseases are extending beyond their historical boundaries, and deforestation is exacerbating flooding downstream and loss of biodiversity. Society is increasingly becoming aware that ecosystem services are not only limited, but also that they are threatened by human activities. The need to better consider long-term ecosystem health and its role in enabling human habitation and economic activity is urgent. In this context IRI conducts research to understand the impact of climate and environmental changes on different sectors including agriculture, water management, human health, and natural disasters. Through exhaustive, rigorous evaluation, analysis and interpretation of remotely-sensed products and in-situ measurements, IRI ensures its partners have access to the most reliable and relevant information about the climate and environment in a format that best informs their decision making and planning. We focus on monitoring satellite-derived and in-situ estimates of precipitation, temperature, vegetation, water bodies, evapotranspiration, and land cover. Ultimately, the new products developed at IRI in partnership with other institutions at national (e.g. NOAA, NASA, USGS) and international (e.g. National Meteorology Agencies, UN FAO) levels are integrated into operational early-warning systems for health, natural disasters, agriculture, and food security. The new products which monitor in almost real-time climate and environmental conditions are made available through two online data bases at IRI called IRI Data Library and Map Room. In this paper we present the products developed at IRI and how they are integrated into Early Warning Systems (EWS). We also discuss IRI's experience in linking EWS into decisions and policies using the fire early warning system as a concrete example.
\end{abstract}

Keywords: Climate; Environment; Early warning systems; Decision making

\section{Background}

Humankind benefits from a multitude of resources and processes that are supplied by natural ecosystems. Collectively, these benefits are known as ecosystem services and include products like clean drinking water, forest, and biodiversity.

As human populations grow, so do the resource demands imposed on ecosystems and the impacts of our global footprint. Natural resources are not invulnerable, nor infinitely available. The environmental impacts of anthropogenic actions are becoming more apparent - air and water quality are increasingly compromised, pests and

\footnotetext{
* Correspondence: pceccato@iri.columbia.edu

${ }^{1}$ The International Research Institute for Climate and Society, The Earth Institute, Columbia University Lamont Campus, 61 Route 9 W, Monell Building, Palisades, NY 10964-8000, USA

Full list of author information is available at the end of the article
}

diseases are extending beyond their historical boundaries, and deforestation is exacerbating flooding downstream and loss of biodiversity. Society is increasingly becoming aware that ecosystem services are not only limited, but also that they are threatened by human activities. The need to better consider long-term ecosystem health and its role in enabling human habitation and economic activity is urgent.

In this context the International Research Institute for Climate and Society (IRI) conducts research to understand the impact of climate and environmental changes on different sectors including agriculture, water management, human health, and natural disasters. Through exhaustive evaluation, rigorous analysis, and interpretation of remotely-sensed products and in-situ measurements, IRI ensures its partners have access to the most reliable 
and relevant information in a format that best informs their decision making and planning. We focus on monitoring satellite-derived and in-situ estimates of precipitation, temperature, vegetation, water bodies, evapotranspiration, and land cover. Ultimately, the new products developed at IRI in partnership with other institutions at national (e.g. National Oceanic and Atmospheric Administration, National Aeronautics and Space Administration, U.S. Geological Survey) and international (e.g. National Meteorology Agencies, U.N. Food and Agriculture Organization) levels are integrated into operational early-warning systems for health, natural disasters, agriculture and food security. The new products which monitor in almost real-time climate and environmental conditions are made available through two online data bases at IRI called Data Library and Map Room.

In this paper we present the products developed at IRI to monitor precipitation, temperature, vegetation, evapotranspiration, and land cover as examples of research and implementation as well as examples of Early Warning Systems developed for forecasting and managing Desert Locust in Africa and forest fires in Indonesia and Latin America. We also present and discuss IRI's experience in linking early warning systems into decision and policies using the fire early warning system as a concrete example.

\section{Main text Improving information \\ Monitoring Climatic and Environmental Factors}

Significant challenges to building the capacity of stakeholders to use climate information in research and decisionmaking activities include the difficulties experienced by many in accessing relevant and timely quality controlled data and information in formats that can be readily incorporated into specific analysis with other data sources (Thomson et al. 2011). Many barriers remain in terms of data, services, practice and policy (IRI 2006) that need to be overcome if climate and environmental information are going to play a significant part in reducing climate related risks (Connor et al. 2010; del Corral et al. 2012).

These barriers include (but are not limited to):

- Lack of clear problem identification for multi-disciplinary research efforts; the purpose of the research may be perceived differently from communities with different objectives.

- Lack of access to relevant local and globally accessible data that may be used to create policy-relevant evidence for local, national, and regional decision-making.

- Lack of capacity to generate new knowledge because there is insufficient capacity to understand, assess, and use climate information (alongside other information e.g. environmental, demographic, etc.), in any specific analysis designed to support a specific research question.

- Lack of effective and available tools to enable the analysis of relevant data in space and time and which communicate easily with other software used for research or knowledge sharing.

- Lack of policies for data sharing as well as technological constraints to knowledge and data sharing that could facilitate networks of researchers to engage with each other around common research agendas.

- Lack of a policy and practice environment that is responsive to new information concerning changes in disease risk.

Accurate and timely information on climatic and environmental factors that influence ecosystems is fundamental to decision-makers if sensible choices need to be made. The information should be understandable and accessible when and where it is needed. Through rigorous evaluation, exhaustive analysis, and interpretation of remotely-sensed products and in-situ measurements, IRI ensures its partners have access to the most reliable and relevant information on climate and environment in a format that best informs their decision making and planning. We focus on monitoring satellite-derived and insitu estimates of precipitation, temperature, vegetation, water bodies, evapotranspiration, and land cover to ensure that their dissemination is done easily and in almost real-time through two online data bases at IRI called the Data Library and Map Room.

As its name suggests the IRI Data Library is organized as a library; a collection of both locally held and remotely held data sets, designed to make the data more accessible for the library's users. Data sets in the library come from many different sources and many different "data cultures" in many different formats. By "data set" we mean a collection of data organized as multidimensional dependent variables, independent variables, and sub-data sets, along with the metadata (particularly metadata on purpose and use) that makes it possible to interpret the data in a meaningful manner.

The Ingrid programming language, which provides the infrastructure for the Data Library, is an environment that allows working with data sets (for example, read, write, request, serve, view, select, calculate, and transform). It hides an extraordinary amount of technical detail from the user, letting the user think in terms of manipulations of data sets rather than manipulations of files of numbers. Among other things, this hidden technical detail could be accessing data on servers in other places, doing a calculation only on the small needed 
portion of a data set, or translating to and from a variety of formats and between "data cultures".

Thus the Data Library is a very powerful open-source computational engine that offers, at no cost to the user, the opportunity to:

- Access, manage and manipulate any number of datasets from a variety of earth science and climate-related topics; - Create analyses of data (including climate and health data) ranging from simple averaging to more advanced Empirical Orthogonal Function (EOF) analyses using the Ingrid programming language;

- Monitor past, climate/environmental conditions with maps and analyses;

- Create multi-dimensional visual representations of climate, including animations over time;

- Customize and download data plots and maps in a variety of image and data formats, including those compatible with geographical information systems (GIS) or other software for data visualization.

Traditional GIS platforms are now widely used. However they are designed with space in mind and have limited functionality for temporal analysis. Furthermore traditional GIS are unable to readily process the vast quantities of space-time data associated with, for example, the outputs of a global climate model. The IRI Data Library overcomes the limitations imposed by GIS platforms by being based on a much more general multi-dimensional data model that includes both space and time dimensions. All datasets, including GIS features (such as points, lines, and polygons) are geo-located and temporally referenced in a uniform framework. Functions and operators in the Data Library use this framework to perform a wide range of analysis that integrates climate/ environmental datasets. Large data sets such as the 100-year climate change simulation results are available through the Data Library's cataloging and data transfer protocol support. The Data Library's interface and functions can be used to access shared repositories in different parts of the world.

The IRI Climate Data Library can be used via two distinct mechanisms that are designed to serve different communities. Expert Mode serves the needs of operational practitioners and researchers that have an indepth knowledge of the functionality of the system and are able to customize it to their own specific needs. The Data Library programming language (Ingrid) can be used by advanced users to develop custom functions and perform tailored analyses. This functionality is widely used around the world by climate researchers as Expert Mode allows users with programming skills a very extensive level of personalized functionality. Online tutorials, examples, and function definitions are part of the Data Library.
In contrast to Expert Mode the Map Rooms provide easy access to point-and-click map-based user interfaces that are built on Data Library infrastructure. The Map Rooms are the result of collaborative negotiations around information needs and make specific data and products for a region or time period available for a specific purpose to specific users and decision makers. The data and maps in these Map Rooms are available for quick and easy download to the user's desktop.

\section{Monitoring precipitation}

In countries where monitoring precipitation is a major problem due to the insufficient coverage of rain gauges, it is necessary to use precipitation estimations derived from satellite measurements. There are many different precipitation estimates derived from satellites (Ceccato and Dinku 2010). These include the Climate Prediction Center (CPC) Merged Analysis of Precipitation (CMAP); Global Precipitation Climatology Project (GPCP); CPC MORPHing technique (CMORPH); Tropical Rainfall Measurement Mission (TRMM); and African Rainfall Estimation (RFE), which are available at different spatial and temporal resolutions ranging from $11 \mathrm{~km}$ to $250 \mathrm{~km}$ (spatial resolution), and from 3-hourly, daily, ten-days to monthly (temporal resolution). Those products are first validated with rain gauge measurements (Dinku et al. 2007; Dinku et al. 2010; Dinku et al. 2011) and then made accessible via the IRI Data Library (Ceccato and Dinku 2010). Ultimately, new rainfall estimate products integrating rain gauge data are developed in collaboration with National Meteorology Agencies to improve the quality of the estimations.

Using rainfall estimate products updated approximately every 10 days through the Africa Data Dissemination Service (ADDS), which is maintained by the United States Geological Survey (USGS) and supported by the U.S. Agency for International Development (USAID), we have developed a web-based Malaria Early Warning System (MEWS) interface which enables the user to gain a contextual perspective of the current rainfall season by comparing it to previous seasons and recent short-term averages.

This interface is in the IRI Data Library and takes the form of an online 'clickable map': http://iridl.ldeo. columbia.edu/maproom/.Health/.Regional/.Africa/.Malaria/. MEWS/. It displays the most recent dekadal rainfall map (Figure 1) over which national and district administrative boundaries and the epidemic risk zone can be overlaid (in this case as a guide rather than an absolute mask which excludes districts of local interest).

These visual features can be toggled on or off and the user can zoom in to any region for more clarity. In addition, the map can be downloaded in different formats compatible with common Image Analysis and Geographical Information Systems (GIS) software such as 


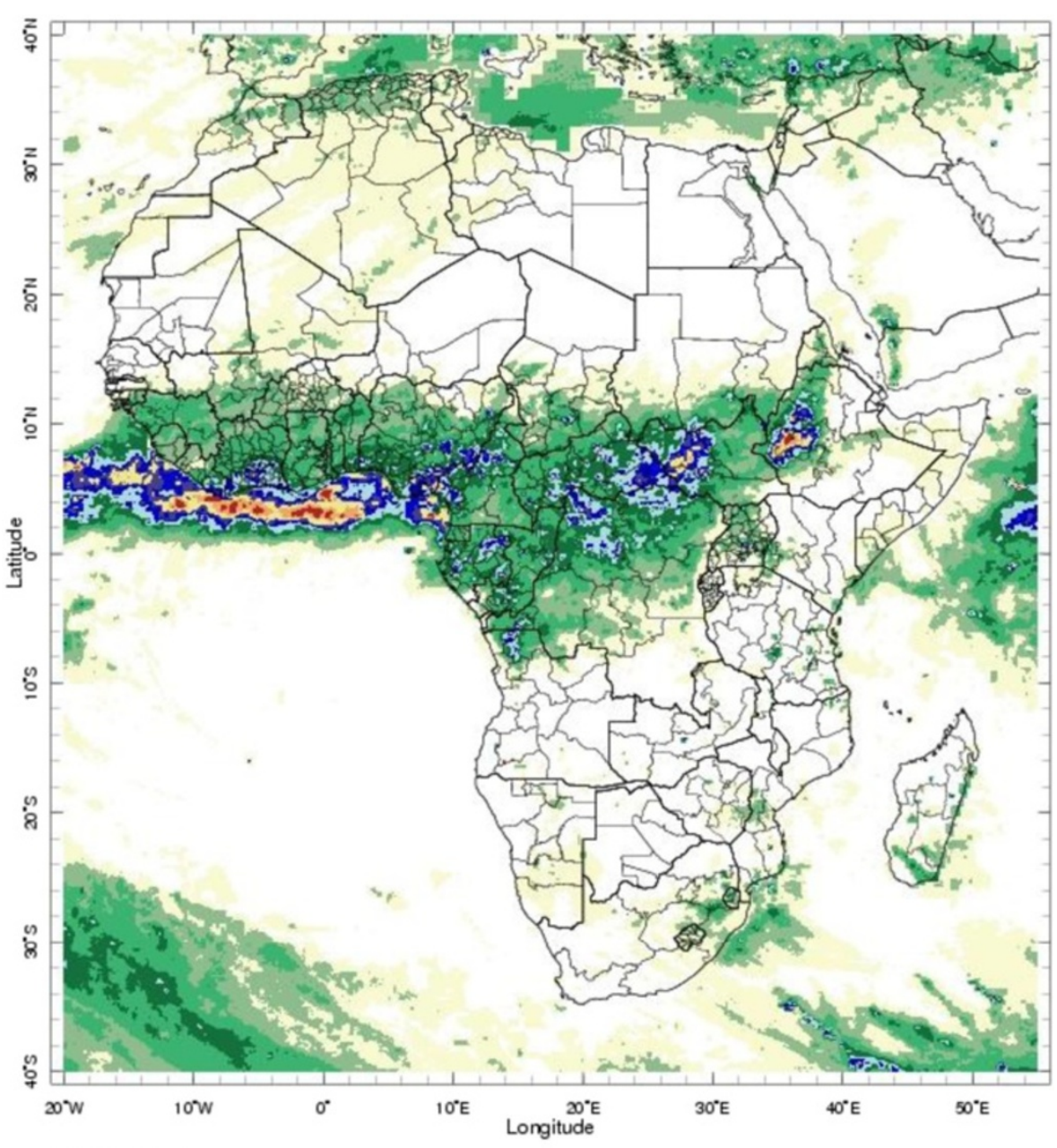

11-20 May 2013

\begin{tabular}{|c|c|c|c|}
\hline \multicolumn{4}{|c|}{ Dataset Documentation } \\
\hline \multicolumn{4}{|c|}{$\begin{array}{l}\text { Precipitation Estimates } \\
\text { Data: Dekadal precipitation estimates on a } 0.1 \times 0.1 \mathrm{deg} \text {. lat/lon grid } \\
\text { Data Source: Climate Prediction Center/Famine Early Warning System (CPC/FEWS } \\
\text { RFE2.0** }\end{array}$} \\
\hline \multirow{2}{*}{\multicolumn{4}{|c|}{$\begin{array}{l}\text { Epidemiological Mask } \\
\text { Data: Mask illustrating areas where malaria is considered to be epidemic. Areas where } \\
\text { malaria transmission is considered absent or endemic are therefore excluded. This mask is } \\
\text { based purely on climatic constraints to malaria transmission, and does not yet account for } \\
\text { areas in the northern and southern margins of the continent where control has eliminated } \\
\text { malaria risk. } \\
\text { Reference: WHO: Final report on the 3rd meeting of the RBM Technical Resource Network } \\
\text { on Epidemic Prevention and Control. Geneva: World Health Organization; } 2002 \text {. } \\
\text { *More dekadal and daily data from FEWS is available from the Africa Data Dissemination } \\
\text { Service. }\end{array}$}} \\
\hline & & & \\
\hline & & Download Layer & Download Data \\
\hline$\frac{\text { Figure as }}{\underline{\text { PDF }}}$ & Figure as JPEG & GeoTiff for GIS & Data for GIS \\
\hline$\frac{\text { Colorscale as }}{\underline{\text { PDF }}}$ & Colorscale as JPEG & NCOIII IOI UID & \\
\hline
\end{tabular}

Figure 1 MEWS ‘Clickable Map’ for Rainfall Monitoring 11-20 Feb 2013. 
ArcView $^{\circledR}$ or HealthMapper (free GIS software developed by UN World Health Organization).

Dekadal rainfall can be spatially averaged over a variety of user-selected areas, including administrative districts and $11 \times 11 \mathrm{~km}, 33 \times 33 \mathrm{~km}, 55 \times 55 \mathrm{~km}$ and $111 \times 111 \mathrm{~km}$ boxes. Upon the selection of this sampling area and a specific location of interest (by clicking on the map at a location of interest), four time-series graphs are generated (Figure 2). These time-series provide an analysis of recent rainfall with respect to that of recent seasons and the long-term series. A description of the time-series figures, the data used, and its source are also provided.

The Map Room allows a large variety of users to access rainfall estimates from satellite measurements. The rainfall products are used inter alia for health (forecasting the risk of malaria transmission due to the development of mosquitoes following favorable rainfall conditions) (Ceccato et al. 2005, Ceccato et al. 2007a), for pest management (monitoring where in the desert rain can create good conditions for the desert locust to breed) (Ceccato et al. 2007b), and for agriculture and index insurance (Hansen et al. 2007, Hellmuth et al. 2009).

\section{Monitoring temperature}

The estimation of near-surface temperature $\left(T_{a}\right)$ is useful for a wide range of applications such as agriculture, climate-related diseases, and climate change studies. However, the derivation of near-surface air temperature (typically measured at $2 \mathrm{~m}$ ), from the land surface temperature $\left(\mathrm{T}_{\mathrm{s}}\right)$ derived from satellite is far from straightforward. At IRI, we are investigating new methods to estimate air temperature based on remotely-sensed products. We have found that the Moderate Resolution Imaging Spectroradiometer (MODIS) sensor of Land Surface Temperature (LST) during the overnight pass was suitable to estimate minimum air temperature (Vancutsem et al. 2010). We then used the MODIS LST on board the AQUA satellite, which passes over Africa at 1:30 a.m. to map minimum air temperature on an 8-day composite at $1 \mathrm{~km}$ spatial resolution (Vancutsem et al. 2010).

While minimum Land Surface Temperature (LST) derived from MODIS night-time images provides a good surrogate for minimum air temperature $\left(T_{a}\right)$, the retrieval of maximum air temperature is less straightforward. Maximum air temperatures can differ from LST by as much as 20 degrees Celsius depending on the ecosystem and the time of the year (Vancutsem et al. 2010). We developed a new approach to estimate maximum $\mathrm{T}_{\mathrm{a}}$ from minimum LST using a diurnal cycle climatology model based on surface weather observations of $T_{a}$ and cloud-cover information. It is important to note that diurnal cycle parameters (i.e. phase and amplitude) are site dependent. They are also sensitive to altitude and seasons. It is therefore important to determine the diurnal cycle locally to account for these temporal and spatial variations. In this context, a gridded data set such as WORLDCLIM (Hijmans et al. 2005) can depict this variability in the space and time domain. Maximum $\mathrm{T}_{a}$ maps were created based on AQUA-MODIS LST nighttime images and climatology data derived from WORLDCLIM. The WORLDCLIM database provides invaluable information on the monthly average of maximum and minimum air temperature at $1 \mathrm{~km}$ spatial resolution. These inputs allowed us to characterize the diurnal cycle (amplitude and phase) and determine maximum $\mathrm{T}_{\mathrm{a}}$ by extrapolating in time minimum $\mathrm{T}_{\mathrm{a}}$ according to the determined diurnal cycle.

We proposed to estimate maximum air temperature using observations from polar orbiting satellite MODIS through the extrapolation of the minimum temperature derived from MODIS according to the diurnal cycle. The diurnal cycle parameters (i.e. phase and amplitude) are determined locally using data from the WORDCLIM database. The proposed approach was applied over four different areas in Africa (Eritrea, Ethiopia, Botswana, and Madagascar) based on measurements collected in 28 different stations over the period 2002-2008. Resulting maps were validated with $\max$ Ta measured at 2 meters at 28 stations located in Botswana (8 stations), Eritrea (4 stations), Ethiopia (8 stations), and Madagascar (8 stations) for the time period 2002-2008. (Ceccato et al. 2010).

The method proposed was found to be sufficiently accurate to spatially represent the maximum air temperature measured in-situ in Botswana, Eritrea, and Madagascar. We then developed the new maximum $\mathrm{T}_{\mathrm{a}}$ product in the IRI Data Library based on the MODIS LST 8-day and the WORLDCLIM data (Figure 3). In addition to mapping the maximum $\mathrm{T}_{\mathrm{a}}$, the Map Room allows users to compare the estimated maximum $\mathrm{T}_{\mathrm{a}}$ time series at a clicked location and a measurement of maximum $\mathrm{T}_{\mathrm{a}}$ at the closest station available from the EVE data set produced by the National Oceanic and Atmospheric Administration (NOAA) National Centers for Environmental Prediction (NCEP) Climate Prediction Center (CPC) (Ropelewski and Halpert 1985) (Figure 4).

The minimum and maximum temperatures are operationally used to map risk of malaria transmission in the highlands of Africa where temperature is the limiting factor. In collaboration with NASA and USGS, the minimum $\mathrm{T}_{\mathrm{a}}$ was integrated into a vectorial capacity model (VCAP) (Ceccato et al. 2012). Vectorial capacity is a series of biological features that determine the ability of mosquitoes to transmit Plasmodium. It is defined as the daily rate at which future inoculations could arise from a currently infected case and it is generally used as a convenient way to express malaria transmission risk or the receptivity of an area to malaria. We analyzed the 


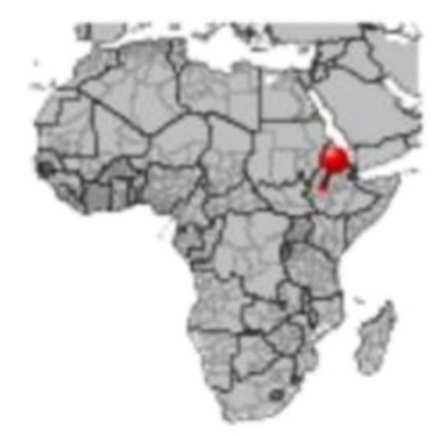

\section{Observations for East Wellega, Oromiya, Ethiopia}

a

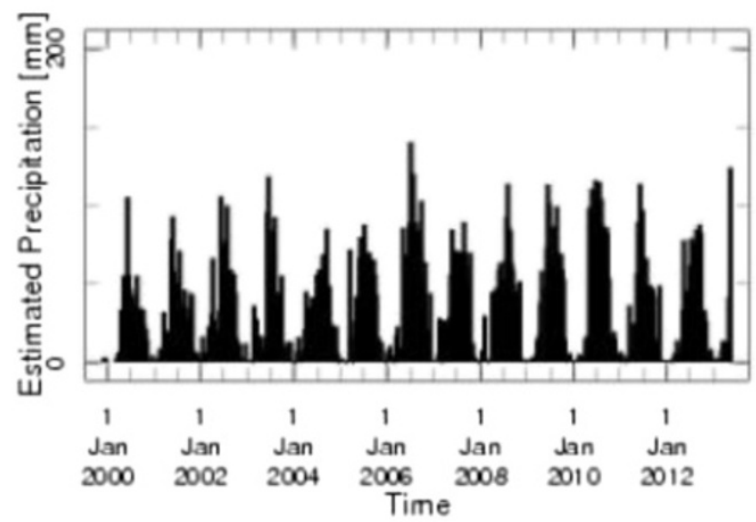

C

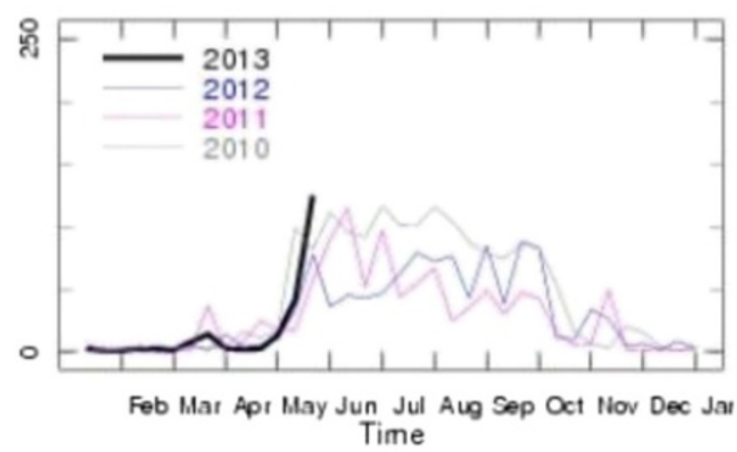

b
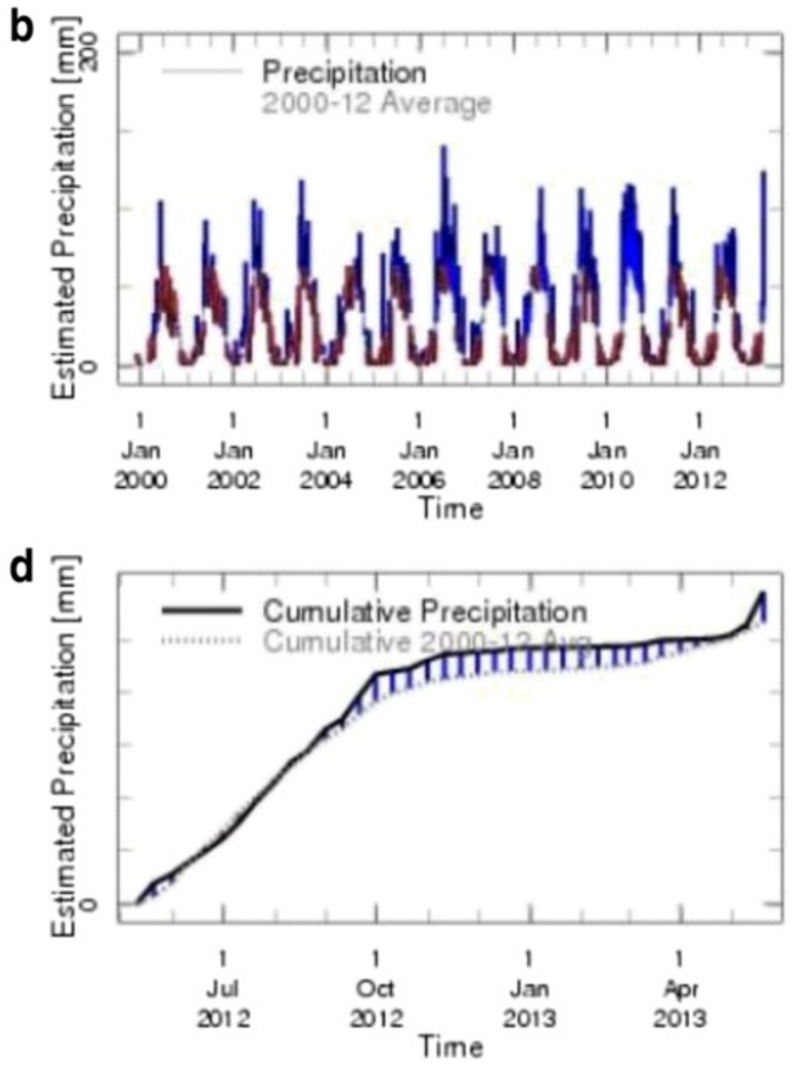

Figure 2 Four time-series graphs are generated and provide an analysis of recent rainfall with respect to that of recent seasons and the long-term series. MEWS 'Clickable Map' for Rainfall Monitoring. Panel a): dekadal (i.e., 10-daily) precipitation estimates for the selected region from Dec 1999 to the present. Panel b): same as (a) (solid black line) with the addition of the recent short-term average precipitation for the same region (grey dotted line). The blue (red) bars are indicative of estimates that are above (below) the short-term average. Note that the short-term average precipitation data has been smoothed. Panel c): same as (a) for the current year (thick black line), as indicated by the axis labels. Precipitation estimates from previous years are also shown (blue-1 yr from present; magenta- 2 yrs from present; grey-3 yrs from present). Panel d): cumulative dekadal satellite-derived precipitation estimates (solid black line) and the cumulative recent short-term average precipitation (grey dotted line) for the most recent 12-month period in the selected region. The blue (red) bars are indicative of estimates that are above (below) the short-term average.

new VCAP in relation to rainfall, temperature, and malaria incidence data in the regions of Eritrea and Madagascar. The results showed that the expanded VCAP correctly tracked the risk of malaria both in regions where rainfall is the limiting factor and in regions where temperature is the limiting factor. In collaboration with the
USGS, the VCAP maps are currently offered as an experimental resource for testing within Malaria Early Warning applications in epidemic-prone regions of sub-Saharan Africa through the IRI Map Room: (http://iridl.ldeo. columbia.edu/maproom/Health/Regional/Africa/Malaria/ VCAP/index.html). 


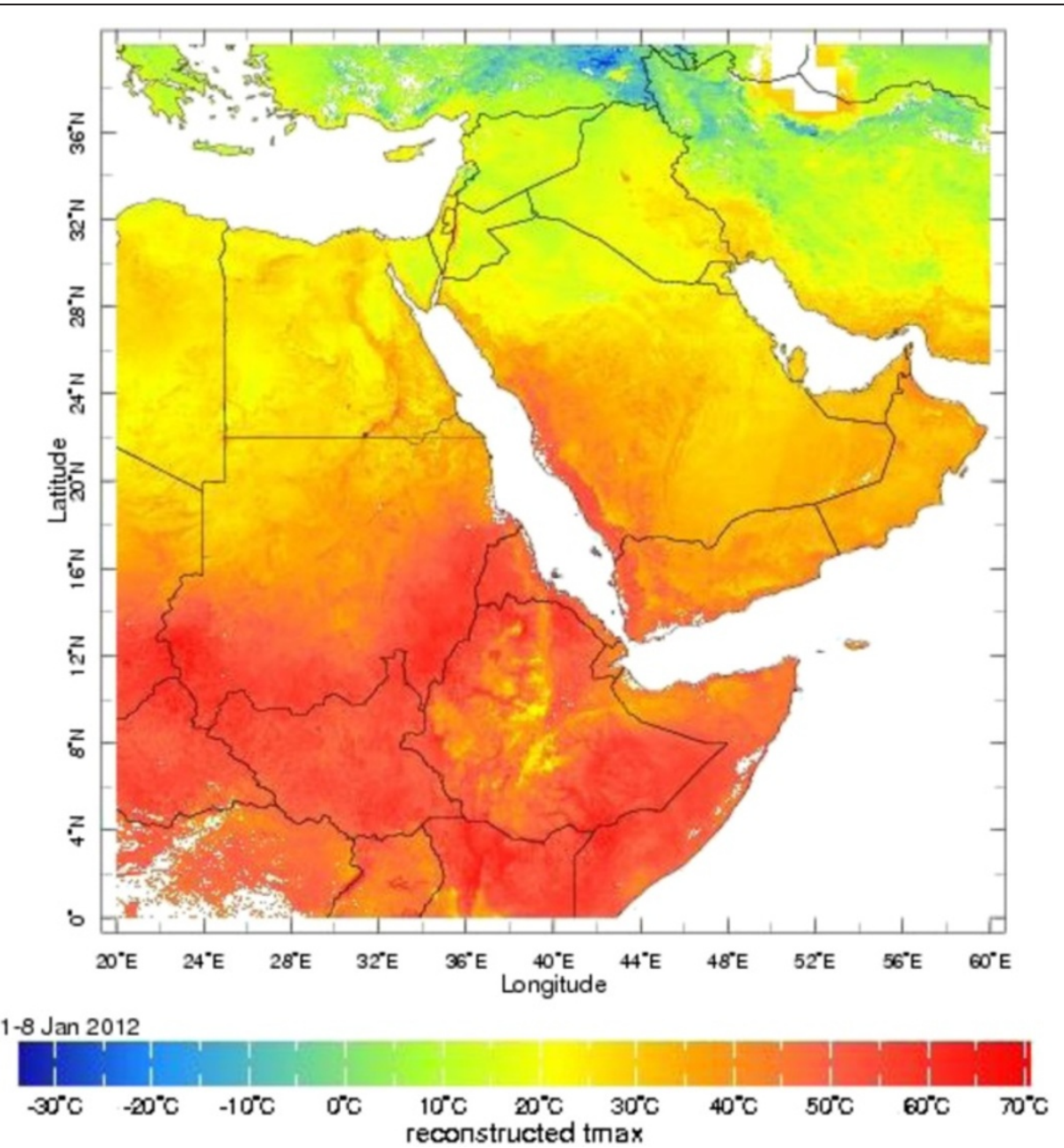

Figure 3 Every 8-days, a maximum $\mathrm{T}_{\mathrm{a}}$ map is constructed based on MODIS AQUA LST night and WORLDCLIM. The spatial resolution is $1 \mathrm{~km}$.

\section{Monitoring vegetation}

Vegetation type and growth stage play an important role in determining mosquito and Desert Locust abundance irrespective of their association with rainfall. The type of vegetation that surrounds the breeding sites, and thereby provides food, potential resting, and protection from climatic conditions are also important in determining the abundance of mosquitoes and Desert Locusts. In order to monitor vegetation, TERRA-MODIS images (at $250 \mathrm{~m}$ spatial resolution) were analyzed at IRI are selected because they provide frequent images at high spatial resolution and are available free of charge (an important requirement considering the economic realities of the countries in the affected region).

The products (vegetation indices 16-day L3 Global 250 M SIN GRID V004) are automatically downloaded from the USGS Land Processes Distributed Active Archive Center (LanDAAC) and provided to the user community via the IRI Data Library web site: http://iridl.ldeo.columbia.
edu/SOURCES/.USGS/.LandDAAC/.MODIS/. The users can download either the raw data - the single channels in the blue, red, near-infrared (NIR), and short-wave infrared (SWIR) wavelengths in different formats compatible with common Image Analysis and Geographical Information Systems (GIS) software - or the Normalized Difference Vegetation Index (NDVI) and Enhanced Vegetation Index (EVI). Using the IRI Data Library, the users can remotely (via Internet):

- Combine the different channels to create their own tailored vegetation indices for monitoring (e.g., vegetation status in terms of moisture content by using a combination of the NIR-SWIR (Ceccato et al. 2002),

- Visualize a color composite of the SWIR-NIR and red channels (red-green-blue) where the vegetation appears in green, the bare soils in brown and the water in blue (Figure 5), 


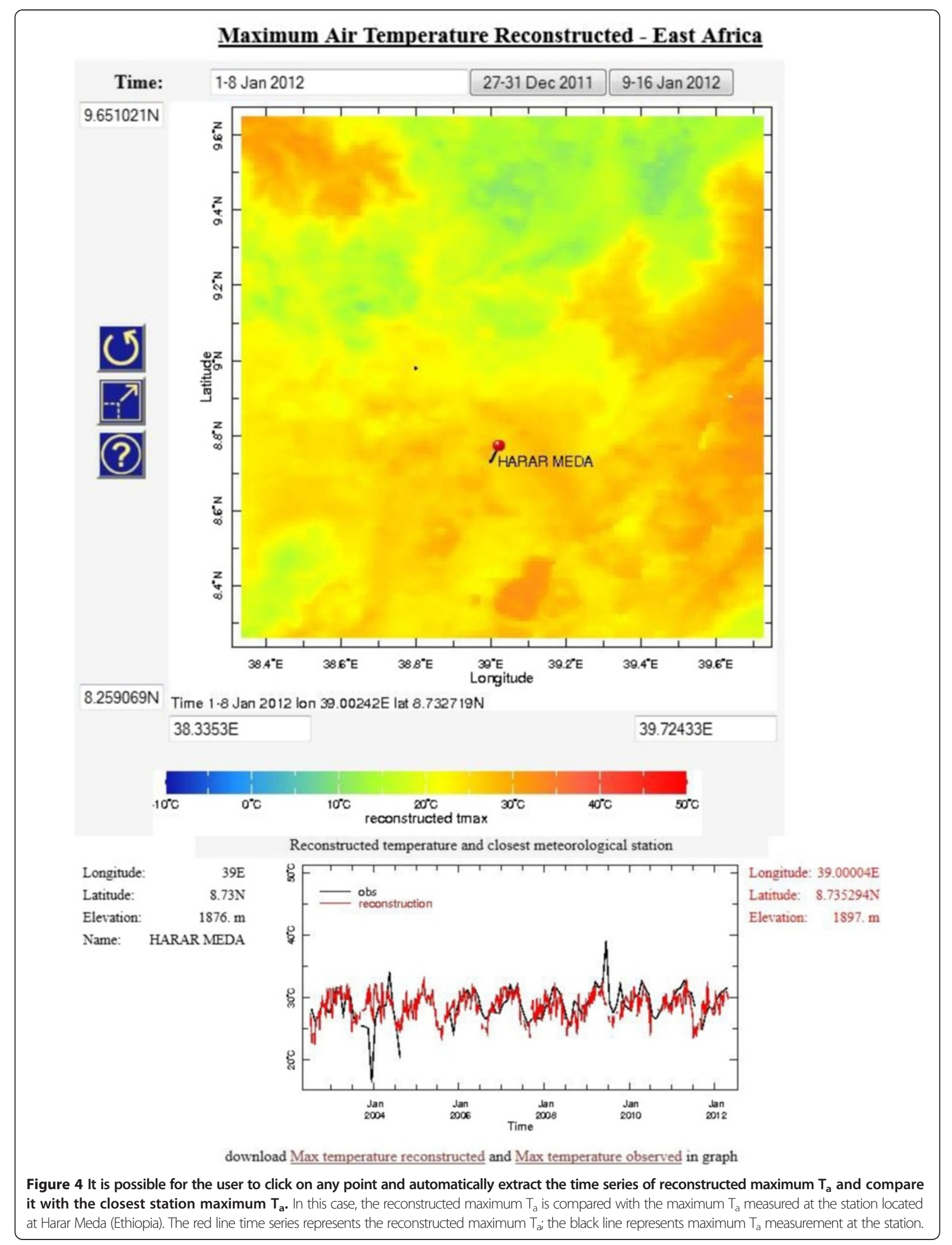


- Integrate the color composite into GIS software with ancillary data such as roads and villages,

- Extract weighted averages of the different indices per GIS layers, such as district contours or any other shape file,

- Create long-term series of vegetation indices.

The Map Room allows a large variety of users to access vegetation from satellite measurements. The vegetation products are used inter alia for health (forecasting the risk of malaria transmission due to the development of mosquitoes following good vegetation conditions) (Ceccato et al. 2007a, Baeza et al. 2013; Martin et al. 2007), for pest management (monitoring where in the desert vegetation can create good conditions for the desert locust to breed) (Ceccato et al. 2006, Ceccato et al. 2007b); and for agriculture and index insurance (Hansen et al. 2007, Hellmuth et al. 2009). The MODIS products are also used to create new indices to monitor vegetation moisture content which is an important factor for monitoring drought (Ceccato et al. 2002). At IRI, we have developed new methods to assess land surface moisture in semi-arid Sahel based on indices using the middle infrared from MODIS (Olsen et al. 2013).

\section{Monitoring water bodies}

The main challenge to identifying water surfaces from remotely sensed data is the high variability of their spectral signatures. The spectral property of water is determined by the electromagnetic interaction of light with the constituent components of water via absorption or scattering processes either within the water column, at the water surface, or on the bottom of the water. These constituents are: the phytoplankton (chlorophyll-a), the suspended sediments (i.e. solid particulate matter) resulting from erosion process, and the colored dissolved organic matter resulting from the degradation of biological organisms. All these constituents vary in character and amount with the limnological/optical types, season, cyclic change of biological activity, and human impact, and play an important role in determining intensity of the absorption and scattering processes. Consequently, the waterleaving radiance detected by the sensor shows great spatial and temporal variability, which makes its reliable discrimination particularly difficult (Gond et al., 2004).

IRI uses a methodology developed by Pekel et al. (2011) to detect open water surfaces on near real-time to identify these water bodies. The method is based on a colorimetric approach of the signal. The rationale is that the perceived color in a color composition is directly determined by the shape of the spectral signature of the target. Consequently, it is possible to associate a land surface type to a range of colors.
The method includes three steps. First, the daily MODIS surface reflectance images are composited on a 10-day basis ( 1 to 10,11 to 20 , and 21 to the end of each month) using the mean compositing algorithm (Vancutsem et al. 2007). This procedure averages the cloud-free reflectance values from both AQUA and TERRA after a quality control based on the MODIS standard data quality flags, and allows consistent (both spatially and temporally) cloud-free imagery. Second, the 10-day middle infrared, near infrared, and red bands were assigned respectively to the red, green, and blue components of the RGB color space and transformed into the hue, saturation, and value components of the HSV color space based on a standardized colorimetric transformation as defined by Smith (1978). Finally, thanks to a large sampling of "open water surfaces" and "other land surfaces" spread both in time (i.e. different seasons and different years) and space (i.e. different land surface types), the spectral signatures and the colorimetric properties of these two clusters were characterized. Therefore a set of thresholds were identified (Pekel et al. 2011) and applied on the Hue and Value subspaces to detect the open water surfaces on a 10-day basis at $250 \mathrm{~m}$.

This approach was used at IRI to monitor water bodies in Siberia (Amstislavski et al. 2013) where the late arrival of freezing temperatures in autumn, followed by earlier spring thaws and more open water, delays transmigration of the Nenet tribes and reduce herders' access to healthcare.

\section{Monitoring evapotranspiration}

Improving regional estimates of evapotranspiration is crucial for understanding land surface-atmosphere interactions especially in climatic transition regions. Studies conducted at IRI evaluate and adapt a daily version of the two layer model based on the Priestley-Taylor (PT) equation for multiple stresses in semiarid regions at daily-time intervals. Remote sensing variables such as surface temperature and albedo were introduced in a new model formulation to minimize the use of climatic inputs.

Model outputs were compared with eddy covariance data during the growing season. The best model performance corresponded to runs with $f_{S M-S W C}, f_{P A R}$ and Leaf Area Index from MODIS. Evapotranspiration was estimated within the uncertainty of the eddy covariance measurements in the Sahel in Africa $\left(r^{2}=0.86\right.$; Mean Absolute Error $=13.54 \mathrm{Wm}^{-2}$ ) and in the Mediterranean grassland $\left(r^{2}=0.75 ; \mathrm{MAE}=11.44 \quad \mathrm{Wm}^{-2}\right)$. When upscaling the model with Meteosat Second Generation (MSG) - Spinning Enhanced Visible and Infrared Imager (SEVIRI) data, results were also promising for $f_{S M-A T I}$ $\left(\mathrm{r}^{2}=0.80-0.31 ; \mathrm{MAE}=19.72-9.66 \mathrm{Wm}^{-2}\right)$. Compared with more complex Penman-Monteith (PM) type models at similar savanna and semiarid grassland ecosystems, the 


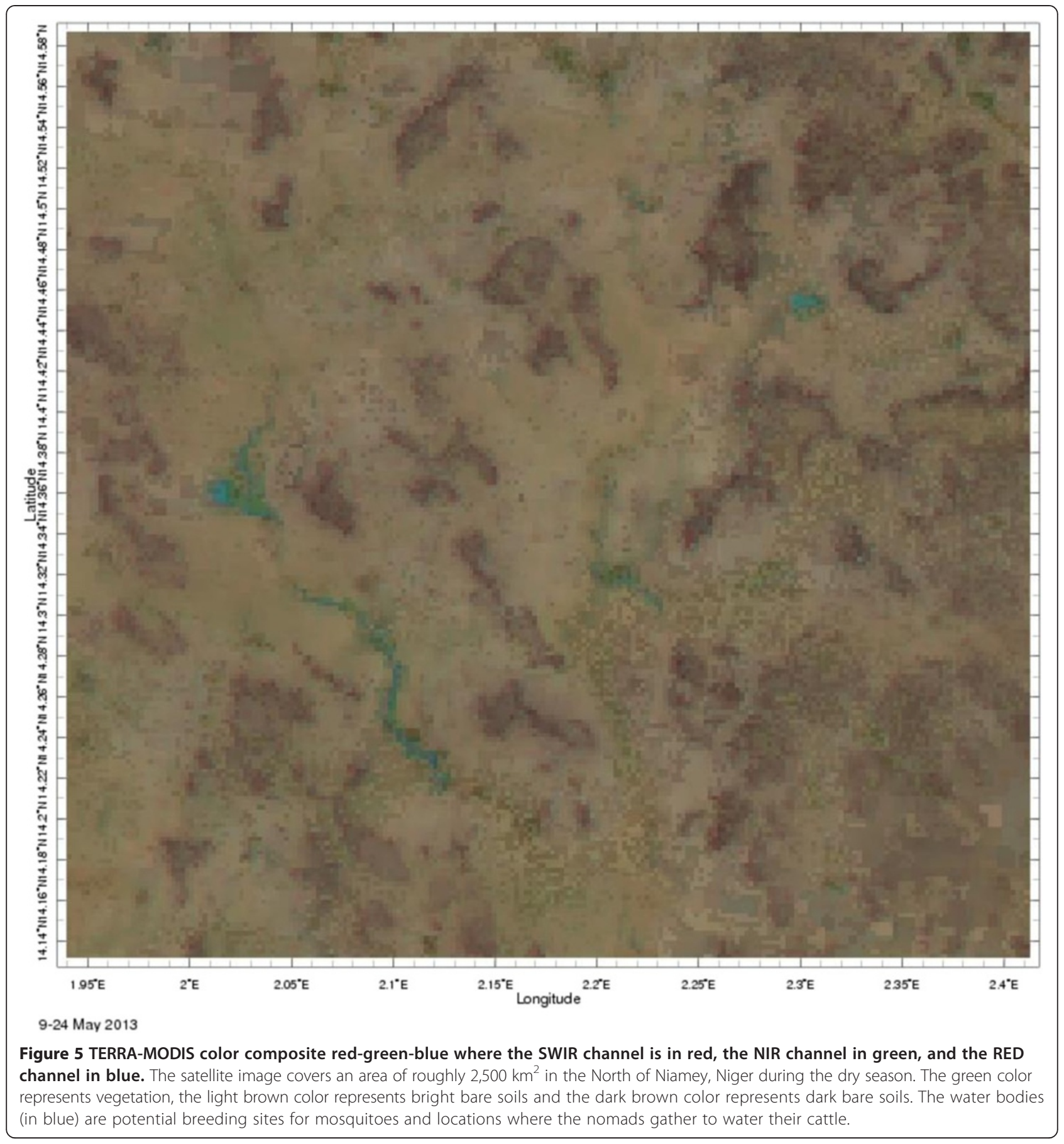

proposed model run with in-situ or satellite $\mathrm{T}_{\mathrm{s}}$ performed within the same range or better than more complex models.

This approach showed potential for regionalization as no optimization is required and the only input variables required, apart from routinely available satellite products, are maximum air temperature and the available energy (Garcia et al. 2013). Evapotranspiration products are currently under development using MSG - SEVIRI images that can help improve the estimation of drought conditions in Africa. Evapotranspiration products are currently evaluated for use in index insurance.

\section{Monitoring land cover}

The use of remote sensing images in accurate agriculture applications has steadily increased in the last decade. In particular, remotely sensed agricultural monitoring has received a lot of attention due to the strong impact on food security. Early production estimation can be very 
important for farmers' economic planning, agronomic field management, and yield price. Hence, there is a rapidly growing interest in methods for automatic early crop identification in agricultural research. In the literature, many crop classification methods propose the use of low spatial resolution images such as MODIS.

The use of MODIS observations is beneficial as it allows global monitoring every two weeks. On the other hand, the major limitation to monitoring the state of global agricultural production using MODIS data is the low spatial resolution of this sensor $(250 \mathrm{~m} /$ pixel $)$. At this moderate resolution, the information contained in a single MODIS pixel is a mixture of single compounds, thus making the characterization of field properties a challenging task. In fact, in order to perform a reliable analysis, the sensor's spatial resolution should theoretically be, at most, the size of the field of interest. Temporal resolution of sensors also plays an important role in recognizing crop types. The use of repetitive satellite observations covering the same area at different dates allows for the characterization of the spectral features of crops during their phonological vegetation cycle. For this reason, most techniques aiming at crop classification are based on the analysis of multi-temporal phenological profiles. These profiles are constructed by multi-temporal NDVI (Normalized Difference Vegetation Index) images belonging to the crop vegetation cycle. These methods rely on the assumption that different crop types have different NDVI profiles during the entire growth season. Discrimination between NDVI profiles from different crop types is therefore made possible. However, this family of approaches also has its limitations. For instance, the cited methods require that the NDVI profiles of all samples belonging to a same crop type are related and a low intra-variability throughout the year. This assumption is not always true since crops belonging to a same type may have different maturity process. For example, a high variability is observed in NDVI profiles of crops belonging to the same type but planted at different dates. Another limitation from these state-of-the art techniques is that crop identification relies heavily on the temporal monitoring during the whole growing season. Consequently, in order to classify a specific area, repetitive observations must be available all along the growth season.

In this context, real-time early crop identification is not possible with the classical NDVI-based approach. At IRI we are investigating new alternative techniques to perform early crop identification without waiting to the end of the season. In particular, we are exploring the use of hyperspectral data and LANDSAT images which provide an increase of the available spectral data. The analysis of Hyperion hyperspectral data obtained in the middle of the growing season has led to promising results regarding crop discrimination. The study showed the strong influence of the stage of growth (i.e. the degree of crop maturity) on the spectrum morphology in the near-infrared. Second, the analysis of NDVI time series showed that early discrimination of crops is a challenging task and that the maximum NDVI is the most discriminative parameter. This latter result has been corroborated by studying the separability of the classes during the first 100 days of the phenological cycle (Valero et al., 2013). Future works will be conducted to study the intra-variability of the crop classes at the early growing stages.

\section{Using seasonal climate forecast to predict fires}

At IRI, research is also conducted to monitor and forecast the climatic and environmental factors that favor natural disasters. In this context research was conducted to understand and forecast the risk of fire occurrences in different regions of the World.

In the year 2005, western Amazon (WA) experienced a " 1 in 100 years" drought and fires were rampant, destroying hundreds of thousands of hectares of forests in Brazil and Peru (Brown et al., 2006 and Gobierno Regional de Ucayali 2006). Increases in fire incidence in the Amazonian regions reflect shifts in many aspects of development, including logging, land use change, infrastructural development, demographic and social changes, and climate variability (Aragão and Shimabukuro 2010; Cochrane and Laurance, 2008; Morton et al. 2008; Van der Werf et al. 2010). To what extent the climate component alone determines and can potentially be used to predict fire anomalies was addressed at IRI by initially comparing western Amazon precipitation and fire anomalies during the dry season (July, August and September-JAS) from 2000-2010. The Moderate Resolution Spectroradiometer (MODIS) Active-Fires (AF) product (Justice et al. 2002) was averaged over the western Amazon domain $\left(14^{\circ} \mathrm{S}-3^{\circ} \mathrm{S}\right.$ and $\left.76^{\circ} \mathrm{W}-70^{\circ} \mathrm{W}\right)$ and then standardized. Rain gauge data from the Peruvian Meteorological Service (Servicio Nacional de Meteorologia e Hidrologia-SENAMHI) were used, in conjunction with rain gauge data from Brazil, to develop a regional gridded rain gauge-only dataset. The gridded data were then averaged over the WA domain to calculate the Standardized Precipitation Index (SPI) (McKee et al. 1993), which is the number of standard deviations that the observed cumulative precipitation deviates from the climatological average.

Although it was expected that overall fire variability should respond to precipitation departures, the correlation between the 2 variables during the 2000s was impressively high $(R=-0.89)$. Precipitation in the Amazon has been shown to respond to sea surface temperature (SST) variability in the tropical Atlantic and Pacific oceans (Yoon and Zeng 2010). This suggests there is a potential for identifying drivers of fire season anomalies rooted in the tropical oceans via the teleconnection 
mechanisms that impact WA precipitation variability. The slow changing nature of SST makes it a desirable prediction variable, having in general better forecast skills in the tropical Atlantic than precipitation in WA for the period leading to the dry season (Barnston et al. 2010).

The domain averaged fire anomalies and SPI (Figure 6) was correlated to evolving SST forecast (Barnston et al. 2010) made in April for May-June-July (MJJ), in May for June-July-August (JJA) and in June for JAS. The correlation fields showed a consistent relationship between WA JAS fire anomalies and the north tropical Atlantic (NTA) over the 3 seasonal SST forecasts used (Figure 7a-c).

The atmospheric mechanism that relates the anomalous warming of the NTA to higher incidence of fires in WA is related to a northward migration of the InterTropical Convergence Zone (ITCZ), which reduces moisture transport from the tropical Atlantic towards the Amazon (Yoon and Zeng 2010) and deficient dry season precipitation (Figure $7 \mathrm{~d}$ ). We then conversely, defined an index based on SST forecast to predict WA fire season (JAS) anomalies. The index consisted of 1-month lead MJJ, JJA, and JAS SST forecast averaged over a domain of coordinates $7.5^{\circ} \mathrm{N}-23.5^{\circ} \mathrm{N}, 75^{\circ} \mathrm{W}-35^{\circ} \mathrm{W}$ (box in Figure 7c). Based on this research, IRI developed a tool to predict JAS fire anomalies. The predictions are presented in section "Forecasting fires in Amazonia" below.

\section{Assessing long-term changes in climatic conditions and their potential impacts on Andean high-altitude ecosystems}

Changes in climatic conditions could have significant impacts on the integrity of Andean high-altitude environments (Herzog et al. 2011). In order to assess long-term changes in several climatic variables such as near-surface and free air temperatures $\left(\mathrm{T}_{\mathrm{a}}\right)$, specific humidity $\left(\mathrm{q}_{\mathrm{s}}\right)$, and dew point $\left(\mathrm{T}_{\mathrm{d}}\right)$, near-term historical climate models' ensemble simulation runs were processed at IRI using the Data Library along with historical weather station data gathered at several Andean meteorological stations.

Mean monthly $\mathrm{T}_{\mathrm{a}}, \mathrm{q}_{\mathrm{s}}$, and $\mathrm{T}_{\mathrm{d}}$ simulation outputs from ECHAM4.5 (Roeckner et al. 1996) ensemble simulation runs, and for the set of ECHAM4.5 grid points located along the axis of the Andes Cordillera, were used to assess statistically significant long-term linear trends in the mean of $\mathrm{T}_{\mathrm{a}}, \mathrm{q}_{\mathrm{s}}$, and $\mathrm{T}_{\mathrm{d}}$ annual time series. ECHAM4.5 data were available for the historical period 1950 to present and were freely downloadable at: (http://iridl.ldeo.columbia.edu/SOURCES/.IRI/. FD/.ECHAM4p5/.History/.MONTHLY/.PressureLevel-SF/).

The ECHAM4.5 model showed good results in the tropical Andes: for the December-January-February trimester, for instance, ECHAM4.5 near-surface temperature anomaly correlation coefficients ranged from +0.55 to +0.85 in most of the tropical belt $15^{\circ} \mathrm{S}-12^{\circ} \mathrm{N}$, except in the spatial domains $\left[10^{\circ} \mathrm{S}-5^{\circ} \mathrm{S}\right.$ and $\left.70^{\circ} \mathrm{W}-75^{\circ} \mathrm{W}\right]$ and $\left[15^{\circ} \mathrm{S}-10^{\circ} \mathrm{S}\right.$ and $\left.40^{\circ} \mathrm{W}-47^{\circ} \mathrm{W}\right]$ where values drop to almost +0.1 to +0.3 . Analyses of long-term linear trends also included the National Oceanic and Atmospheric Administration (NOAA) - National Centers for Environmental Prediction (NCEP) - Department of Energy (DOE) Reanalysis-2 (NOAA NCEP-DOE Reanalysis-2), which is part of the NCEP/DOE Atmospheric Model Intercomparison Project (AMIP) - II Reanalysis (Kanamitsu et al. 2002). NOAA NCEP-DOE Reanalysis-2 data span the historical period 1979-to present and are also available online at: (http:// iridl.ldeo.columbia.edu/SOURCES/.NOAA/.NCEP-DOE/. Reanalysis-2/.Monthly/.pgb/.pgb/.tmpprs/).

Using the IRI Data Library we were able to display and download ECHAM4.5 individual members and ensemble simulation runs, as well as NOAA NCEP-DOE Reanalysis2 data. We then assessed long-term linear trends, as well as abrupt changes in the mean and the variance of annual climatic time series (Figure 8). The role of El Niño Southern Oscillation (ENSO) dynamics and/or Tropical Atlantic Ocean regimes in the dynamics of the Andean climate was also assessed. Principal Component (PC) analyses were conducted on January-December ECHAM4.5 and NOAA NCEP-DOE Reanalysis- 2 mean monthly $\mathrm{T}_{\mathrm{a}}$ and $\mathrm{q}_{\mathrm{s}}$ anomalies, in order to evaluate the signature of changes in sea surface temperatures in the spatio-temporal patterns of ambient temperatures and specific humidity along the axis of the Andes Cordillera. Analyses of these data indicated that free air temperatures have significantly increased in

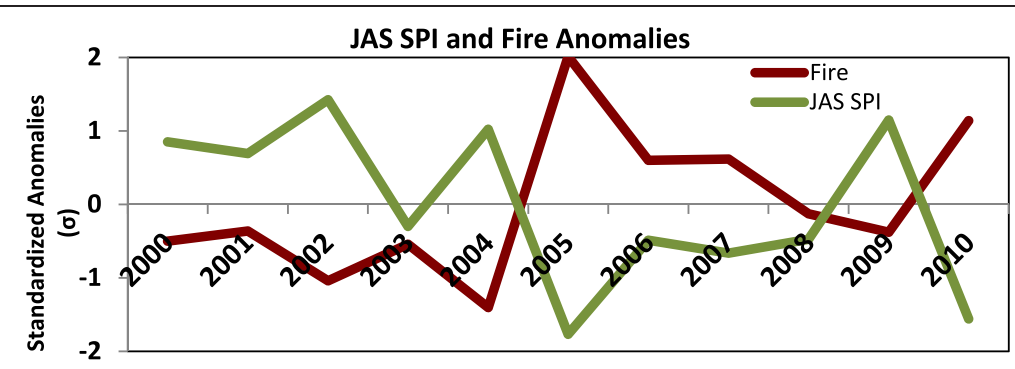

Figure 6 Time series of the July-August-September standardized precipitation index (SPI) and standardized fire anomalies averaged over the western Amazon domain $\left(14^{\circ} \mathrm{S}-3^{\circ} \mathrm{S}, 76^{\circ} \mathrm{W}-70^{\circ} \mathrm{W}\right)$. 


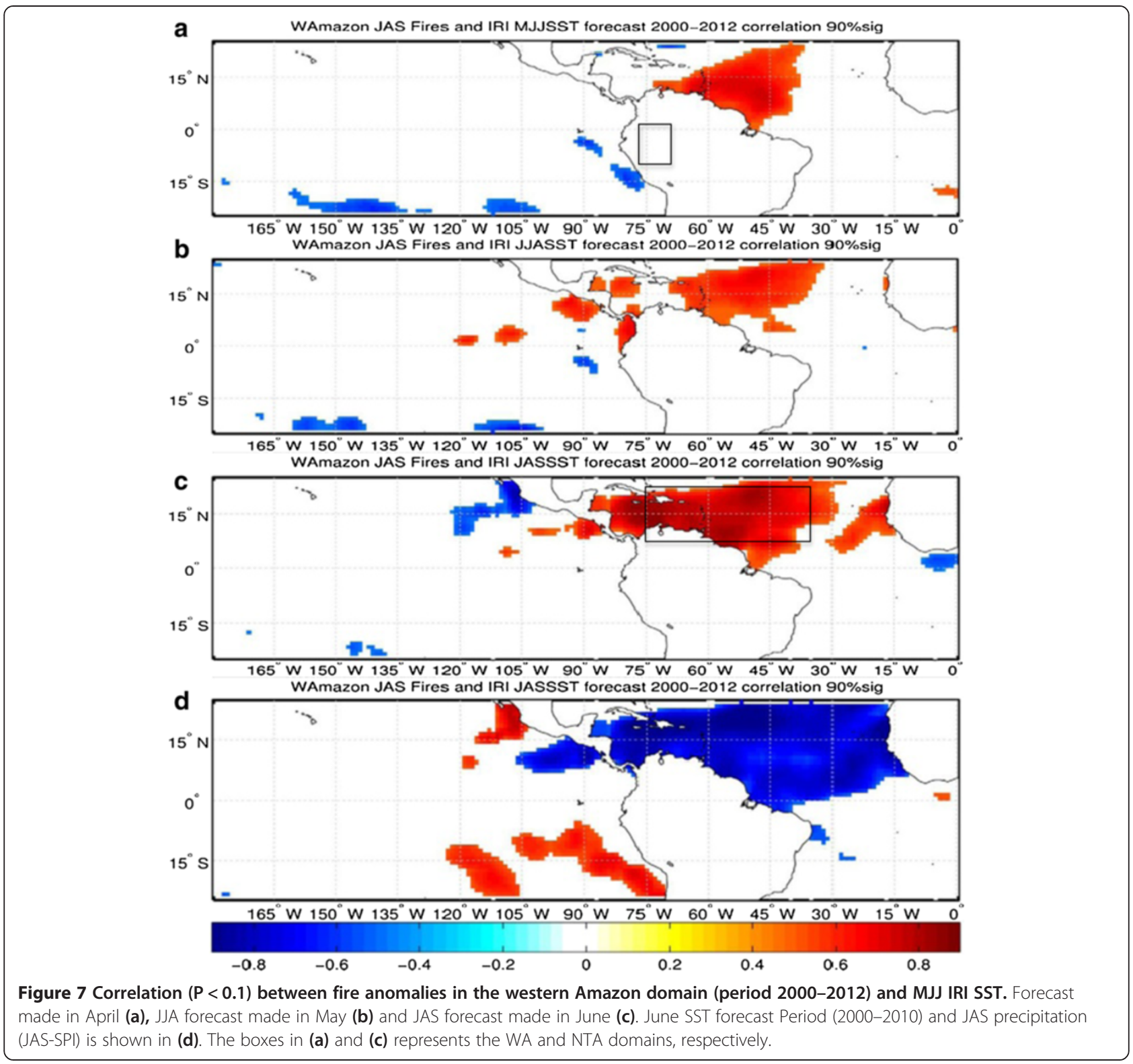

the tropical belt $15^{\circ} \mathrm{N}$ to $15^{\circ} \mathrm{S}$, and particularly at higher elevations ([100-400 $\mathrm{mb}]$ and [300-600 mb] according to ECHAM4.5 simulation outputs and Reanalysis-2 data, respectively), at a rate that exceeds 1.5 times what is simulated for the lower troposphere (Ruiz, 2013).

Analyses also suggested that these long-term changes in free air temperatures in the upper levels of the $15^{\circ} \mathrm{S}$ to $15^{\circ} \mathrm{N}$ latitudinal range were strongly dependent on changes (long-term warming and normal variability) in sea surface temperatures in both the Indo-Pacific and Tropical Atlantic oceans, and their synergistic effects. The IRI approach, combined with observed and projected climate trends derived from ground-truth data and climatic reconstructions of pre-instrumental periods, significantly improved our knowledge on local climatic conditions prevailing in Andean ecosystems. They also provided better assessments of short- to medium-term climate change scenarios that could be faced by these highly strategic environments. Outputs of these analyses thus provided numerous and valuable elements for the integrated climate-related vulnerability assessments of many sectors, including biodiversity, environmental health, water and energy supply, and agriculture.

\section{Early warning systems}

In this section we provide examples of how we have improved the way information is generated, presented, and accessed using two Early Warnings Systems (EWS) developed for i) Desert Locusts and ii) fires in Indonesia 


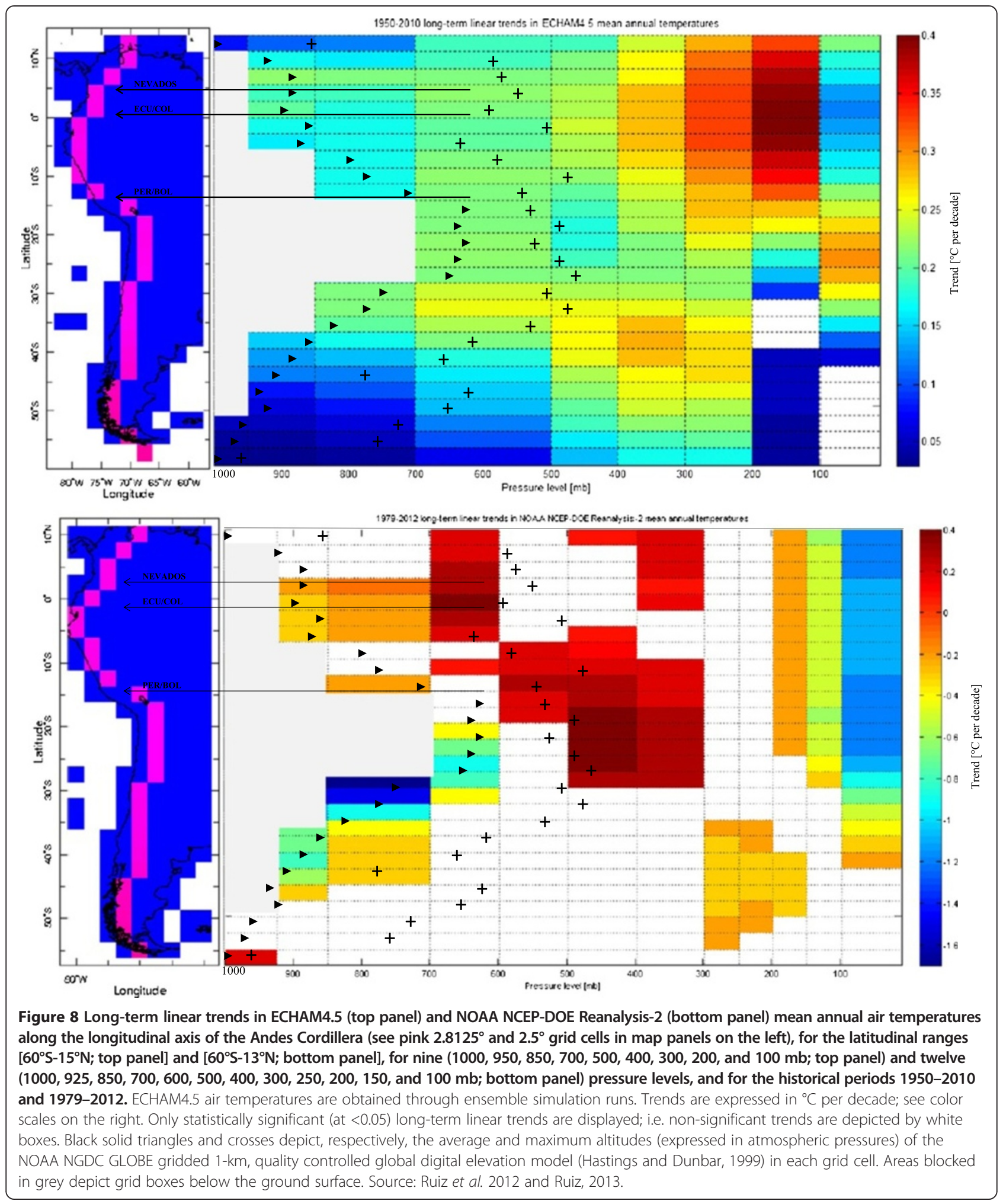

and Latin America. The two EWS were developed in collaboration with the user community and helped us understand what type of research can help resolve user demands and needs.
The only way to achieve a sustainable improvement in climate risk management (or development outcomes) is through the collaborative efforts with climate info users and providers. At IRI, we enable and engage these 
collaborations and structure them into the projects. The following examples show how we have created, in collaboration with the Ministries of Agriculture and United Nations Food and Agriculture Organization (FAO), an EWS for Desert Locust, and with the local government in Central Kalimantan, Indonesia, an EWS for forest fires.

\section{Desert locust early warning system}

In 1994 FAO established the "Emergency Prevention System for Transboundary Animal and Plant Pests and Diseases" (EMPRES programme - Desert Locust Component) to strengthen national control teams and improve early warning systems. The philosophy adopted by FAO to fight Desert Locusts is based on early detection, warning, and control in order to prevent locust upsurges that could lead to plagues.

To detect Desert Locusts at an early stage, survey teams must visit potential breeding areas to assess the condition of the habitat and the state of any Desert Locust population that may be present (Symmons and Cressman, 2001). The potential breeding areas are spread over vast, sparsely populated, and difficult-to-access regions. Availability of transportation, staff resources, and operational allotments are major limiting factors for systematic surveillance. To avoid random search for vegetation in the desert and allow more efficient monitoring over large scale, an EWS was developed from the early 1990s, based on satellite imaging (Hielkema and Snijders, 1994) for detecting vegetation and GIS for managing the Desert Locust information. This was improved during the last 10 years (Ceccato 2005) and was installed in Locust Control Units (LCU) located in each of the affected countries (Ceccato 2005). A similar but global GIS was set up in the Desert Locust Information Service (DLIS) at FAO headquarters (Rome, Italy) and has been operational since the mid-1990s (Healey et al. 1996).

In order to avoid extensive and costly operations, it is necessary to detect Desert Locust populations at the outbreak or early upsurge stages before their populations can expand into full-scale plagues. To achieve early detection of Desert Locust, survey teams must visit potential breeding areas to assess the condition of the habitat and the state of any Desert Locust populations. The potential breeding areas cover areas that are spread over vast regions that are remote and difficult to access. To survey them involves considerable preparation and travel time, costly transport, as well as significant financial and staff resources. Reaching them all on a regular basis presents serious logistical problems. Some limiting factors include the availability of transportation and operational allotments Survey teams cannot afford to monitor the potential areas by guesswork, without knowing exactly where to find vegetation conditions that are favorable to
Desert Locust reproduction. The use of satellite images combined with GIS provide an early warning system which can be used to direct field survey teams toward regions with a high potential for Desert Locust infestation and to estimate control measures required.

In collaboration with DLIS, IRI has developed products to estimate ecological conditions and rainfall events in the Desert Locust recession area. The maps and analysis products (Figure 9) illustrate recent climate conditions, such as rainfall and vegetation, which provide ideal breeding conditions for the locusts.

This Map Room is used operationally by the Ministries of Agriculture in twenty-three countries between Mauritania and India and the Food and Agriculture Organization to develop bi-monthly bulletins on the Desert Locust situation (http://www.fao.org/ag/locusts/en/info/info/index.html) and issue alerts for control measures to be taken by the countries.

\section{Fire early warning system in Kalimantan}

Through the results of the studies conducted at IRI, we provided evidence that fire activity is associated with rainfall anomalies, as well as evidence of a potentially predictive relationship with the ENSO state (NINO 4 index) with a lead time of 1-2 months. Based on these relationships, we developed tools in the Data Library to i) monitor rainfall anomalies and ii) forecast fire occurrence in the four provinces based on antecedent NINO4 Index. To assist local stakeholders in their efforts to monitor fire occurrence and minimize its impacts, we first developed an online tool which would enable them to view satellite rainfall anomalies and, as a result, take necessary action.

The tool is available on the Internet (http://iridl.ldeo. columbia.edu/maproom/.Fire/.Regional/.Indonesia/.Dekadal_ Rainfall/) and allows the users to automatically extract time series of anomalies for a specific location and district levels (Figure 10).

We then developed a tool available on the Internet (http://iridl.ldeo.columbia.edu/maproom/.Fire/.Regional/. Indonesia/.NINO4.html) that allows the users to visualize the NINO4 Index and assess the probability of fire occurrence. We have been preparing, in collaboration with the Indonesian meteorological service (BMG), experimental seasonal forecasts of rainfall anomalies over the region with lead times from 1 to 6 months, using a dynamical regional climate model RegCM3, driven by outputs from a global climate model ECHAM4. The coupled ECHAM4-RegCM3 modeling forecast system reflects the impacts of NINO4 over the Pacific as well as other driving factors such as the Indian Ocean Dipole. The regional model simulates and forecasts rainfall over Kalimantan is still in development and it is expected to provide in the 


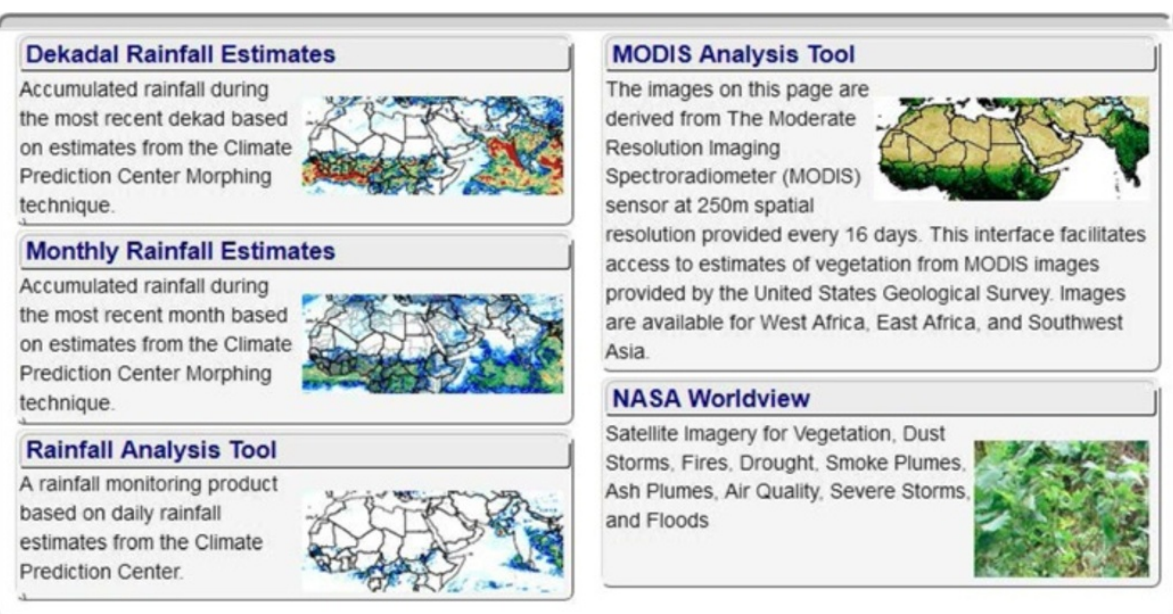

Figure 9 Desert Locust Map Room. The map room includes information on precipitation, vegetation presence and vegetation indices to allow the Desert Locust control teams to identify regions at risks in the desert areas between Mauritania and India.

near future higher accuracy of rainfall anomalies forecast than the single use of NINO 4.

\section{Forecasting fires in Amazonia}

Climate is an important driver of fire variability in western Amazon, but not its sole predictor. Fire dynamics also depend on socio-economic aspects including replacement of forests by crops and pastures, timber extraction, and infrastructure development, being nonexistent or rare in a large extent of the study area (Figure 11a) where human activity is low. This characteristic restricts our prediction to grid cells where some inter-annual fire variability is observed.

The JAS fire season prediction model developed at IRI was based on linear regression models using the NTA SST forecast index (described in section "Using seasonal climate forecast to predict fires" above) as predictor. The NTA index time series were derived from 1-month lead retrospective IRI SST forecasts (Barnston et al. 2010) for MJJ, JJA, and JAS (i.e. made in April, May, and June respectively). The time series were then regressed onto the gridded values of JAS MODIS-AF anomalies in western Amazon for the period 2000-2012, following the method used in Fernandes et al. 2011. A 95\% prediction confidence interval (CI) was used to verify the model prediction in 2005 and 2009, used here as examples of an anomalously dry and wet seasons, respectively.

The linear regression model reproduced the observed positive fire anomalies in 2005 in most grids within 95\% of confidence interval of validation using the NTA predicted in April (MJJ), May (JJA) and June (JAS). The forecast made in April was very similar to that of May. The sparse distribution of predicted grid cells were mostly due to the sparse character of fire occurrence in this region as mentioned previously, and reflected in the number of years that fires in JAS were detected by MODIS (Figure 11a).

The 2009 dry season in WA was anomalously wet and similarly to 2005 , the prediction based on the regression models was able to simulate the negative anomalies in fire occurrence within the 95\% CI (Figure 12a and b) in most grid cells. As in the case of 2005, the prediction made using the MJJ NTA-SST forecast was very similar to JJA. As the 2013 dry season approached, we are presenting the forecast for this year's fire season (2013), indicating a slightly enhanced activity predicted for JAS.

This tool, associated with the ability to predict fire season anomalies with a three month lead time in western Amazon, has the potential to aid decision makers to establish an early warning system or other appropriate course of action before the fire season begins.

\section{Discussion}

\section{Linking early warning systems to policies}

Opportunities and need for informed decision making/ policy development

The development and use of early warning systems offers policy makers a cost-effective and efficient means to identify risks in advance to enable them to take critical steps to decrease impacts related to climate. The identification of high risk areas enables resources to be mobilized in advance to mitigate negative impacts and bolster response efforts in the event an impact occurs.

\section{Guidance on linking early warning and decision support tools to policies}

In 2006, the IRI and Bogor Agriculture University (Institut Pertanian Bogor or IPB) partnered with CARE Indonesia and the provincial government in Central Kalimantan, 


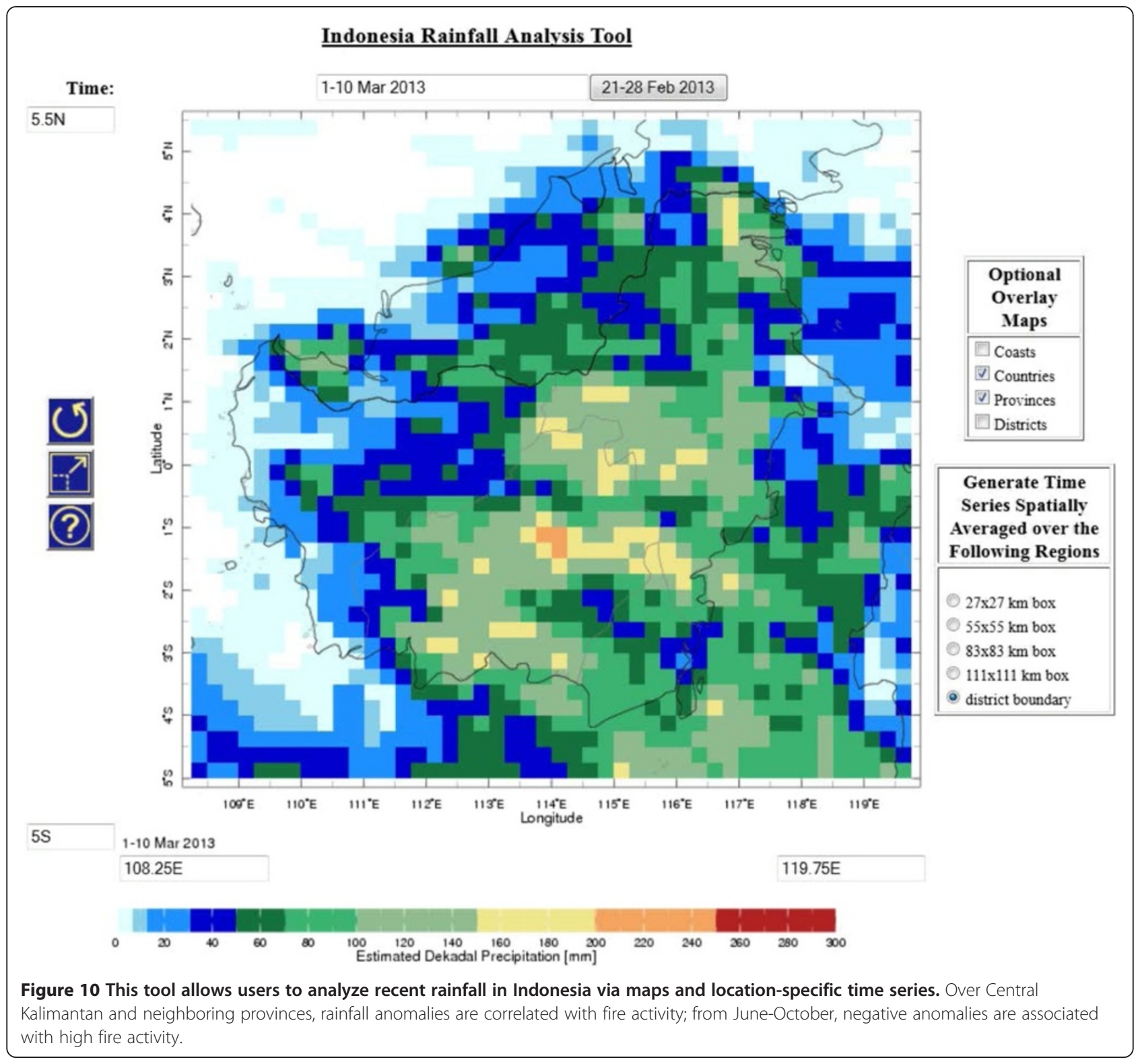

Indonesia to develop a seasonal early warning system that signals increased chance of uncontrolled spread of peatland fires to enable proactive measures in high-risk years. Widespread peatland fires pose a serious risk to public health, livelihoods, and conservation efforts in Indonesia, and contribute significantly to climate change. During the 1997-98 El Niño event, Indonesia experienced below normal rainfall which contributed to conditions that resulted in the massive uncontrolled spread of peatland fires, causing major regional haze, millions of cases of respiratory problems, billions in economic losses, and an estimated equivalent of $13-40 \%$ of global carbon emissions from fossil fuels during that time (Page et al. 2002). The collaborative research implemented under this partnership yielded important guidance and lessons learned in linking early warning to policies and proactive management of climate risks as outlined below and further detailed in Someshwar et al. 2011.

\section{Mapping the policy and institutional landscape}

Characterization and response to risk depends largely on stakeholder perceptions of risks and the strategies stakeholders have embraced to protect their interests. Governance and institutions play a critical role in framing risks and formalizing responses to climaterelated risks. Thus, mapping the policy and institutional landscape for climate risk management and decision processes is a critical first step for linking early warning tools to policy and decision-making framework. 


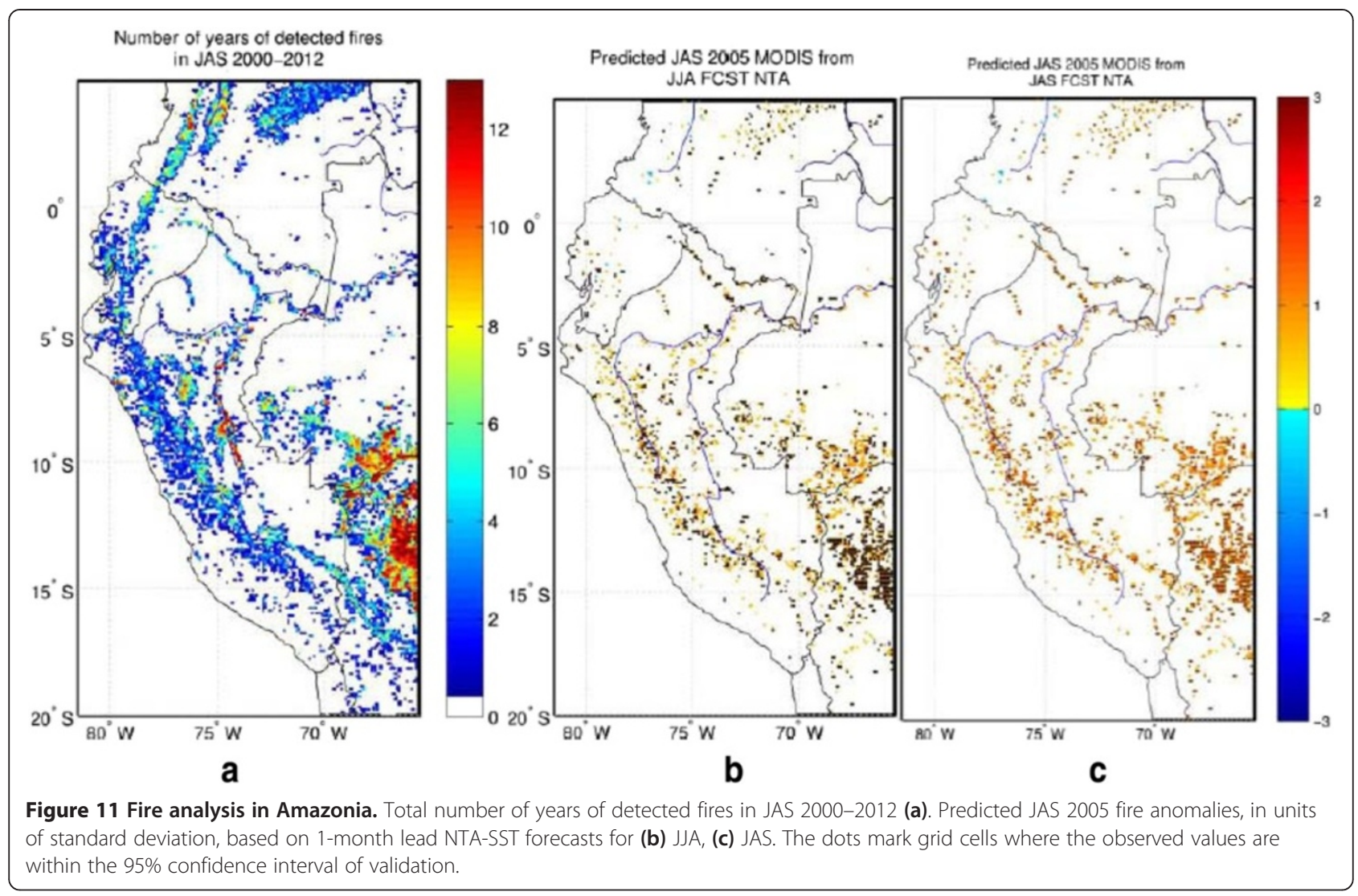

In the context of the Peatlands fire risk management project, social scientists worked to better understand the institutional context for fire management at district and provincial levels. This included an investigation of the current fire early warning system and practices, the roles of government agencies and local communities, and the availability of alternatives to fire use for land clearing, through district- and provincial-level interviews and community meetings. Through this research, it was determined that decisions about the fire management system used by farming households and community plantations are primarily made at the provincial level, with their implementation (and funding) delegated to the district and village levels. The clarity of roles and responsibilities mean that a relatively small number of key staff at the provincial level needed to be convinced of the utility of seasonal fire risk information. This is one of the factors that facilitated government action and enabled the development of provincial level fire use policy that was guided by the fire early warning tool.

\section{Enabling policy environment}

Linking early warning and other decision support tools with policy is greatly facilitated when governments and other decision-making entities are receptive to new ideas and flexible in their adoption. In the peatlands initiative there was a strong desire to shift current regulations, which proved fortuitous for the project. In 2006, the governor of Central Kalimantan banned all use of fire by households and community plantations for land clearing purposes. This legislation was highly unpopular with farmers and plantation owners alike because while theoretically, there are alternatives for land clearing, the manual labor, machinery, and herbicides required are not only cost prohibitive for subsistence farmers, but the alternatives do not deal as effectively with pest problems as fire. In August 2008, shortly after the release of the fire early warning tool and training on its use, provincial officials adjusted the policy to soften the fire ban and included provisions for the use of seasonal climate forecast information in deciding when to allow fire for land clearing.

\section{Champion stakeholders}

It is critical that international development agencies and research institutions develop a partnership with a strong, trusted local institution to follow-up on the day-to-day working relationships with local stakeholders. In the case of the aforementioned Peatlands project, the relationship that CARE Indonesia had built over several years of on-theground development project work on health and natural resources management in the villages of Central Kalimantan 


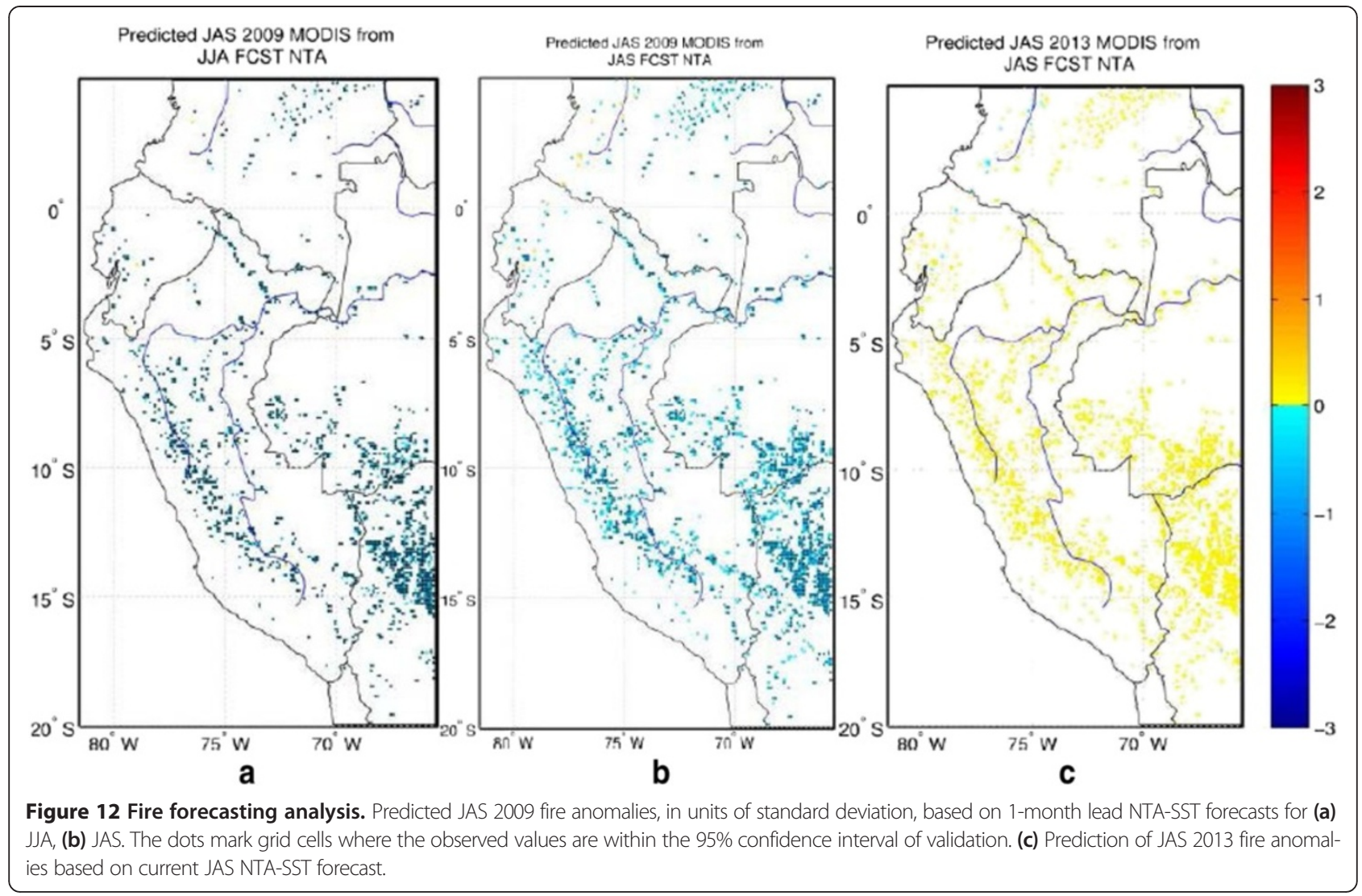

enabled the project to gain acceptance. The everyday working relationship between CARE and the provincial government - e.g., through staff secondment to the Provincial Environment Office - was also very important.

\section{Problem-oriented and inter-disciplinary approach to research}

The development of decision support tools that empower climate informed decision-making requires innovative and interdisciplinary research. In the case of the peatlands project, experts in climate science, remote sensing, forecasters, agricultural scientists, policy experts, economists, and sociologists worked together to better understand the specific challenges that provincial and district-level officials were facing with regard to peatland fires, the institutional context of decisionmaking, and existing local capacity. This enabled project partners to focus research to meet the need for seasonal climate information, as well as updated rainfall information that would be simple to access and understand for policymakers and technical staff alike.

\section{Capacity building and user input into tool development}

The assessment of current scientific knowledge and capacity across the diverse spectrum of stakeholders comprising the climate services value chain helps target entry points for capacity building. Targeting and prioritizing to ensure that the appropriate information for decision making is developed and is of the best possible quality, easily accessible, and effectively communicated. Furthermore it helps ensure that decision-makers understand how to use the information to inform their decisions and that the orchestra of actors are present and prepared to implement the decisions. It is important that decision-makers are integrally involved in the development of the decision tools to best ensure that the decision-relevant information is produced and easily understood to empower the ability for climate-informed decision making, impart a sense of ownership in the tool, along with a sense of satisfaction and pride in its use.

In the case of the Peatland fires project, one of the first activities was to identify the current scientific knowledge and capacity of actors identified in the policy and institutional landscaping effort. Several workshops for district and provincial-level officials were convened in which the research and concepts behind seasonal fire early warning were presented, and participants had the opportunity to interact with the tool and engage in discussions and ask questions. Through these exchanges, notes were made on the most common gaps in understanding and a user-friendly training manual on the fire early warning tool was developed. This manual explains 
how the tool works and provides a step-by-step guide to its use, hands-on exercises, and is accessible online in English and Indonesian.

\section{Barriers and challenges to tool adoption encountered in Indonesia}

One of the primary barriers to the uptake of the seasonal fire early warning system in Central Kalimantan is that this EWS has historically been used reactively. In this system, government agencies would disseminate weather forecast information on a 1-2 day time horizon and the information would in turn be picked up by entities with a mandate to fight fires. Complementing the use of short-range weather information with forecast information with a longer time horizon with greater uncertainty proved challenging.

It did not help that the governance of fire suppression is one-way and top-down. In this system, regulations are promulgated at the provincial level, policied at the district level, and acted upon at the village and farm levels, with very little opportunity for feedback from the local level into the decision-making process. Unreliable access to communication and high diversity of local fire situations, contrasted with the use of a hierarchical approach to information dissemination and use was another barrier. The majority of the work was deployed by governments and did not always benefit from the participation and stakeholder value maximization. Furthermore, the farmers were frustrated by the emphasis on penalties for the use of fire.

Limited capacity and understanding of seasonal early warning across the full range of relevant government agencies inhibited the adoption and advancing of the intervention. Furthermore, staffing limitations made it difficult to expand the existing system into a more comprehensive system offering risk management that provides choices of action over longer time horizons.

Recommendations on overcoming barriers and challenges A number of critical next steps were identified at the completion of the Peatlands project. One important step is to promote good governance in land use management. It is believed that by bringing together the formal and informational actors involved in the climate services value chain through the consensus-building sessions and online support forum, this will help facilitate the shift to science-based, participatory, consensual, and transparent decision-making. Stakeholders with a remit for anticipatory action should be targeted in these discussions.

Despite the Peatland project's good efforts on stakeholder training, much remains to be done. General training on probabilistic fire risk forecasts, including how to interpret and use the information, ranks very high on the list of follow-up activities.

It was highlighted that an incentive system would greatly help enhance the uptake of the tool. These incentives should be carefully designed accounting for the available alternative to fire use, and their practical applicability in the agro-ecological and socio-cultural context of Central Kalimantan. Development of this system should involve research on the relative costs of alternatives to using fire; whether household, community, village or some higher order group payments are more appropriate; and the elements of payments, such as how, when, and to whom they will be made.

\section{Conclusion}

In this paper we presented the products developed to monitor precipitation, temperature, vegetation, evapotranspiration, and land cover as examples of research and implementation conducted at IRI. We presented examples of Early Warning Systems developed for forecasting and managing Desert Locusts in Africa and forest fires in Indonesia and Latin America. Early warning systems for different applications are in place and used effectively in a number of countries. They are mostly composed of a number of information streams for monitoring and forecasting environmental and climatic factors. The Remote Sensing and Seasonal Climate Forecast inputs to these information streams have been subject to extensive research to validate their skills (Dinku et al. 2011; Vancutsem et al. 2010, Barnston et al. 2010; Ceccato et al. 2012). However, to be fully operational the systems must be integrated into an operational decision/action framework. We presented and discussed IRI's experience in linking early warning systems into decision and policies using the fire early warning system as a concrete example.

Competing interests

The authors declare that they have no competing interests.

\section{Authors' contributions}

PC contributed to the synthesis of the sections "Introduction", "Improving information", "Early warning systems". KF contributed to the synthesis of sections on "Using seasonal climate forecast to predict fires" and

"Forecasting fires in Amazonia". DR contributed to the synthesis of section on" Assessing long-term changes in climatic conditions and their potential impacts on Andean high-altitude ecosystems". EA contributed to the synthesis of section "Linking early warning systems to policies". All authors read and approved the final manuscript.

\section{Acknowledgement}

Pietro Ceccato, Katia Fernandes, Daniel Ruiz and Erica Allis received funding from NOAA grant NA100AR4310210 to conduct research and develop products presented in this paper.

Responsible editor: Michael Schaepman

\section{Author details}

'The International Research Institute for Climate and Society, The Earth Institute, Columbia University Lamont Campus, 61 Route 9 W, Monell Building, Palisades, NY 10964-8000, USA. ${ }^{2}$ Unidad Académica Civil, Ambiental e Industrial, Escuela de Ingeniería de Antioquia, km 02 + 200 Vía al Aeropuerto José María Córdova, Municipio de Envigado, Antioquia, Colombia. 
Received: 1 October 2013 Accepted: 17 January 2014

\section{Published: 17 June 2014}

\section{References}

Amstislavski P, Zubov L, Chen H, Ceccato P, Pekel J-F, Weedon J (2013) Effects of increase in temperature and open water on transmigration and access to health care by the nenets reindeer herders in northern Russia. Int J Circumpolar Health 72(Suppl 1), article number 21183

Aragão LECO, Shimabukuro YE (2010) The Incidence of fire in Amazonian forests with implications for REDD. Science 328(5983):1275-1278

Baeza A, Bouma MJ, Dhiman R, Baskerville E, Ceccato P, Pascual M (2013) Long lasting transition towards sustainable elimination of desert malaria under irrigation development in India. Proceedings of the National Academy of Sciences of the United States of America (PNAS) 110(37):15157-15162

Barnston AG, Li S, Mason SJ, DeWitt DG, Goddard L, Gong X (2010) Verification of the first 11 years of IRI's seasonal climate forecasts. J Appl Meteorol Climatol 49:493-520

Brown IFW, Schroeder A, Setzer M, Rios Maldonado D I, Pantoja N, Duarte A, Marengo JA (2006) Monitoring fires in southwestern Amazonia rain forests. Eos Trans AGU 87(26):253-264

Ceccato P (2005) Operational early warning system using SPOT-VGT and TERRAMODIS to predict desert locust outbreaks. In: Veroustraete F, Bartholome E, Verstraeten WW (eds) Proceedings of the $2^{\text {nd }}$ VEGETATION International Users Conference, 24-26 March 2004, Antwerpen. Office for official publication of the European Communities, Luxembourg, p 475. ISBN 92-894-9004-7, EUR 21552 EN

Ceccato P, Dinku T (2010) Introduction to remote sensing for monitoring rainfall, temperature, vegetation and water bodies. IRI Technical Report 10-04, International Research Institute for Climate and Society, Palisades, NY, p 15

Ceccato P, Gobron N, Flasse S, Pinty B, Tarantola S (2002) Designing a spectral index to estimate vegetation water content from remote sensing data (Part 1: theoretical approach). Rem Sens Environ 82(2-3):188-197

Ceccato P, Connor SJ, Jeanne I, Thomson MC (2005) Application of geographical information system and remote sensing technologies for assessing and monitoring malaria risk. Parassitologia 47:81-96

Ceccato P, Bell NA, Blumenthal MB, Connor SJ, Dinku T, Grover-Kopec EK, Ropelewski CF, Thomson MC (2006) Use of remote sensing for monitoring climate variability for integrated early warning systems: applications for human diseases and desert locust management. In: , IEEE International Geoscience \& Remote Sensing Symposium \& $27^{\text {th }}$ Canadian Symposium on Remote Sensing (IGARSS 2006), Denver, Colorado, pp 270-274, Article number 4241221

Ceccato P, Ghebremeskel T, Jaiteh M, Graves PM, Levy M, Ghebreselassie S, Ogbamariam A, Barnston AG, Bell M, Del Corral J, Connor SJ, Fesseha I, Brantly EP, Thomson MC (2007a) Malaria stratification, climate and epidemic early warning in Eritrea. Amer J Trop Med Hyg 77:61-68

Ceccato P, Cressman K, Giannini A, Trzaska S (2007b) The desert locust upsurge in west Africa (2003-2005): information on the desert locust early warning system, and the prospects for seasonal climate forecasting. Int J Pest Manage 53(1):7-13

Ceccato P, Vancutsem C, Temimi M (2010) Monitoring air and land surface temperatures from remotely sensed data for climate-human health applications. International Geoscience and Remote Sensing Symposium (IGARSS):178-180, Article no 5649810

Ceccato P, Vancutsem C, Klaver R, Rowland J, Connor SJ (2012) A vectorial capacity product to monitor changing malaria transmission potential in epidemic regions of Africa. J Trop Med 2012:6, Article ID 595948, doi:10.1155/2012/595948

Cochrane MA, Laurance WF (2008) Synergisms among fire, land Use, and climate change in the Amazon. Ambio 37(7-8):522-527

Connor SJ, Omumbo J, DaSilva J, Green C, Mantilla G, Delacollette C, Hales S, Rogers D, Thomson MC (2010) Healt hand climate - needs. Procedia Environ Sci 1:27-36

Del Corral J, Blumenthal B, Mantilla G, Ceccato P, Connor SJ, Thomson MC (2012) Climate information for public health: the role of the IRI climate data library in an integrated knowledge system. Geospat Health 6(3):S15-S24

Dinku T, Ceccato P, Grover-Kopec EK, Lemma M, Connor SJ, Ropelewski CF (2007) Validation of satellite rainfall products over East Africa's complex topography. Int J Remote Sens 28(7):1503-1526

Dinku T, Ceccato P, Cressman K, Connor SJ (2010) Evaluating detection skills of satellite rainfall estimates over Desert Locust recession regions. J Appl Meteorol Climatol 49(6):1322-1332

Dinku T, Ceccato P, Connor SJ (2011) Challenges to satellite rainfall estimation over mountainous and arid parts of east Africa. Int J Remote Sens 32(21):5965-5979
Fernandes K, Baethgen W, Bernardes S, DeFries R, DeWitt DG, Goddard L, Lavado W, Lee DE, Padoch C, Pinedo-Vasquez M, Uriarte M (2011) North tropical Atlantic influence on western Amazon fire season variability. Geophys Res Lett 38, L12701

Garcia M, Sandholt I, Ceccato P, Ridler M, Mougin E, Kergoat L, Morillas L, Timouk F, Fensholt R, Domingo F (2013) Actual evapotranspiration in drylands derived from in-situ and satellite data: Assessing biophysical constraints. Remote Sens Environ 131:103-118

Gobierno Regional de Ucayali (2006) Evaluación de impactos ambientales de quema e incendios forestales en la provincia de Coronel Portillo. Gobierno Regional de Ucayali, Pucallpa, Peru

Gond V, Bartholomé E, Ouattara F, Nonguierma A, Bado L (2004) Monitoring and cartography of the water levels of wetlands and easily flooded arid areas with the instrument VEGETATION carried on SPOT-4. Int J Remote Sens 25(5):987-1004

Hansen JW, Baethgen W, Osgood D, Ceccato P, Ngugi RK (2007) Innovations in climate risk management: protecting and building rural livelihoods in a variable and changing climate. J Semi-Arid Trop Agric Res 4(1):1-38

Hastings DA, Dunbar PK (1999) Global Land one-Kilometer Base Elevation (GLOBE) Digital Elevation Model, Documentation, Volume 1.0. Key to Geophysical Records Documentation (KGRD) 34. National Oceanic and Atmospheric Administration, National Geophysical Data Center, 325 Broadway, Boulder, Colorado, USA, p 80303

Healey RG, Robertson SG, Magor JI, Pender J, Cressman K (1996) A GIS for desert locust forecasting and monitoring. Int J Geogr Inf Syst 10(1):117-136

Hellmuth M, Osgood D, Hess U, Moorhead A, Bhojwani H (2009) Index insurance and climate risk: prospects for development and disaster management. Climate and Society No. 2. International Research Institute for Climate and Society, The Earth Institute, Columbia University, Palisades, NY, USA, p 112

Herzog SK, Martínez R, Jørgensen PM, Tiessen H (2011) Climate change and biodiversity in the tropical Andes. Inter-American institute of global change research (IAI) and scientific committee on problems of the environment (SCOPE). São José dos Campos, Paris, p 348, ISBN: 978-85-99875-05-6

Hielkema JU, Snijders FL (1994) Operational use of environmental satellite remote sensing and satellite communications technology for global food security and locust control by FAO: The ARTEMIS and DIANA systems. Acta Astronaut 32(9):603-616

Hijmans RJ, Cameron SE, Parra JL, Jones PG, Jarvis A (2005) Very high resolution interpolated climate surfaces for global land areas. Int J Climatol 25:1965-1978

IRI (2006) A gap analysis for the implementation of the global climate observing system programme in Africa. International Research Institute for Climate and Society, Palisades, NY

Justice CO, Giglio L, Korontzi S, Owens J, Morisette JT, Roy D, Descloitres J, Alleaume S, Petitcolin F, Kaufman Y (2002) The MODIS fire products. Remote Sens Environ 83(1-2):244-262

Kanamitsu M, Ebisuzaki W, Woollen J, Yang SK, Hnilo JJ, Fiorino M, Potter GL (2002) NCEP-DOE AMIP-II Reanalysis (R-2). Bull Am Meteorol Soc 83:1631-1643

Martin V, De Simone L, Lubroth J, Ceccato P, Chevalier V (2007) Perspectives on using remotely-sensed imagery in predictive veterinary epidemiology and global early warning systems. Geospat Health 2(1):3-14

McKee TB, Doesken NJ, Kleist J (1993) The Relationship of Drought Frequency and Duration to Time Scales. 8th Conference on Applied Climatology, Anaheim, California, pp 179-184

Morton DC, Defries RS, Randerson JT, Giglio L, Schroeder W, van Der Werf GR (2008) Agricultural intensification increases deforestation fire activity in Amazonia. Glob Chang Biol 14(10):2262-2275

Olsen JL, Ceccato P, Proud SR, Fensholt R, Grippa M, Ardo J, Mougin E, Sandholt I (2013) Assessment of land surface moisture in semi-arid Sahel from seasonally detrended shortwave infrared reflectance data. Remote Sens 5(6):2898-2927

Page S, Siegert F, Rieley J, Boehm H, Jay A, Limin S (2002) The amount of carbon released from peat and forest fires in Indonesia during 1997. Nature 420:61-65

Pekel JF, Ceccato P, Vancutsem C, Cressman K, Vanbogaert E, Defourny P (2011) Development and application of multi-temporal colorimetric transformation to monitor vegetation in the desert locust habitat. IEEE Journal of Selected Topics in Applied Earth Observations and Remote Sensing 4(2):318-326

Roeckner E, Arpe K, Bengtsson L, Christoph M, Claussen M, Dümenil L, Esch M, Giorgetta M, Schlese U, Schulzweida U (1996) The atmospheric general circulation model ECHAM4: model description and simulation of present-day climate. Max-Planck-Institut für Meteorologie Rep. 218, Hamburg, Germany, p 90 
Ropelewski CF, Halpert MS (1985) Global and regional scale precipitation patterns associated with the El-Nino southern oscillation. Mon Weather Rev 115(8):1606-1626

Ruiz D (2013) daptation strategies to climate change in the tropics: analysis of two multifactorial systems (high-altitude Andean ecosystems and Plasmodium falciparum malaria infections). PhD dissertation in Earth and Environmental Sciences, Graduate School of Arts and Sciences, Columbia University, City of New York, p 383

Ruiz D, Herzog SK, Jørgensen PM, Larsen TH, Martínez R, Nieto JJ, Poats SV, Ohira M (2012) Five-tiered integrated climate-related biodiversity vulnerability assessment in the Tropical Andes. Mountain Research Initiative Newsletter. 7:7-11, Available online at: http://mri.scnatweb.ch/individual-articles-mri-newsno.7-high-resolution/view-category/Page-3

Smith AR (1978) Color Gamut Transform Pairs, Proceedings of the $5^{\text {th }}$ Annual Conference Computer Graphics and Interactive Techniques., pp 12-19, doi:10.1145/800248.807361

Someshwar S, Boer R, Conrad S (2011) Managing Peatland Fire Risk in Central Kalimantan. Indonesia, World Resources Report

Symmons PM, Cressman K (2001) Desert locust quidelines. FAO, Rome. :43, Available: http://www.fao.org/ag/locusts/common/ecg/347_en_DLG1e.pdf

Thomson MC, Connor SJ, Zebiak SE, Jancloes M (2011) Africa needs climate data to fight disease. Nature 471:440-443

Valero S, Ceccato P, Baethgen W, Chanussot J (2013) Identification of Agricultural Crops in Early Stages Using Hyperspectral Remote Sensing Images, Abstract presented at the International Geoscience and Remote Sensing Symposium (IGARSS)., Melbourne, Australia

Van der Werf GR, Randerson JT, Giglio L, Gobron N, Dolman AJ (2010) Climate controls on the variability of fires in the tropics and subtropics. Global. Biogeochem Cycles 22(3), Art No. GB3028 2008, doi:10.1029/2007GB003122 Vancutsem C, Pekel J-F, Bogaert P, Defourny P (2007) Mean Compositing, an alternative strategy for producing temporal syntheses. Concepts and performance assessment for SPOT VEGETATION time series. Intern J Remote Sensing 28(22):5123-5141

Vancutsem C, Ceccato P, Dinku T, Connor SJ (2010) Evaluation of MODIS Land surface temperature data to estimate air temperature in different ecosystems over Africa. Remote Sens Environ 114(2):449-465

Yoon JH, Zeng N (2010) An Atlantic influence on Amazon rainfall. Climate Dynam 34(2-3):249-264

doi:10.1186/2194-6434-1-16

Cite this article as: Ceccato et al: Climate and environmental monitoring for decision making. Earth Perspectives 2014 1:16.

\section{Submit your manuscript to a SpringerOpen ${ }^{\circ}$ journal and benefit from:}

- Convenient online submission

- Rigorous peer review

- Immediate publication on acceptance

- Open access: articles freely available online

- High visibility within the field

- Retaining the copyright to your article

Submit your next manuscript at $\gg$ springeropen.com 